\title{
THE RISE OF THE STATE: BROADBAND POLICY IN NEW ZEALAND 2000-2011
}

\author{
By \\ Jordan Tracy Carter
}

\begin{abstract}
A thesis
submitted to the Victoria University of Wellington in fulfilment of the requirements for the degree of

Master of Arts

in Political Science
\end{abstract}

Victoria University of Wellington 


\section{Abstract}

Between 2000 and 2011, changes in government policy significantly increased the role of the state in telecommunications markets in New Zealand. In both regulatory and investment activities, the historic approach of liberal market regulation was transformed into active intervention. This changed approach aimed at speeding access to high-speed broadband services. There was a remarkable lack of political debate between the major political parties as to the objective being sought, or direction of policy towards greater intervention in order to achieve it.

This research outlines in broad terms the background to the debates underpinning policy change, and the history of New Zealand's approach. It outlines in detail the key policy changes made. In the regulatory domain, four key changes are discussed. These are: the implementation of sector-specific legislation (Telecommunications Act 2001); the decision not to unbundle the copper local loop (2004); amendments to the Telecommunications Act strengthening the regulator and imposing 'operational separation' of Telecom (2006); and the 'structural separation' of Telecom and the debate on regulatory forbearance (2011). By the end of the case period, these changes meant that generic competition law had been replaced by sector-specific legislation, a specialist regulator with broad powers to monitor and regulate the industry, and a leading solution to discrimination issues with the complete ownership separation of network and services in copper and fibre-optic telecommunications networks.

In the investment domain, five key stages are discussed. These are: Project PROBE (2001-4), the Broadband Challenge (2005), the Broadband Investment Fund (2008), the Ultra-Fast Broadband Initiative (2009) and the Rural Broadband Initiative (2009). Together these saw public spending on telecommunications infrastructure rise from nothing in 2000, to a combined package in the two final (and current) initiatives of around $\$ 1.6 \mathrm{bn}$ of public funds. This money combines with private investment to deliver fibre-optic broadband infrastructure to three-quarters of homes, and significant improvements to the availability of higher-speed broadband in rural and remote parts of New Zealand. 
Increasing levels of government intervention in these markets was an opportunity for considerable political contest. Instead the case period 2000-2011 is characterised by similarities rather than differences between National and Labour. The thesis suggests that an explanation for this similarity arose from the perceived importance of high-speed broadband infrastructure for New Zealand's economic prospects, and a shared analysis by Labour and National that market provision would not suffice. This imperative defeated temptations to politicise the project. 


\section{Acknowledgements}

My profound thanks go first to John Leslie, my supervisor. Without his patience and support during the long course of this research, and the difficulties caused by other career activities at various points, the work would never have been done. John: thank you.

Thank you secondly to the School and Faculty at Victoria, for their forbearance and tolerance in dealing with my efforts to juggle academic research with employment and political commitments from 2007 to 2012. The life of a part time thesis student is not very collegial, and I regret not making stronger connections with fellow graduate students.

This thesis would never have occurred without the time provided by my employer, InternetNZ, for me to focus on academic pursuits. My thanks go to Vikram Kumar, Richard Currey and Keith Davidson for encouraging me in this work and for making it possible to do so.

Inspiration for the topic is owed to a range of characters in the industry, the academy and beyond. In forming my thinking many people had an impact, known or not. Particular mention goes to Michael Wigley, Reg Hammond, Susie Stone, Frank March, Chris Abbott, Simon Riley, David Diprose, David Stone and Ross Patterson. My apologies to anyone who I should have mentioned but have not.

Matthew Castle provided sterling service as a proof reader. Thank you Matt!

My family, my friends and my flatmates have provided me with the space to complete this work, and support when another night of work came close to being too much. Thank you to every one of you.

Jordan Carter

28 February 2012, Wellington. 


\section{Table of Contents}

Abstract .




\section{Introduction}

Broadband is a critical enabler of productivity, growth, and economic transformation, yet New Zealand is lagging behind on many broadband indicators. (Clark, 2006)

Broadband uptake in New Zealand has been slow in comparison to many developed countries and it is vitally important for the future and prosperity of the country that this is reversed. (Cunliffe, 2006b)

[W] can't simply do what we've always done. The world is getting more and more competitive every year. So, just like any other country, New Zealand needs to focus its efforts on the things that will really make a difference to our earning power... Fibre right to the home promises huge gains in productivity, innovation, and global reach for New Zealand. Those are the things that will make our economy richer. (Key, 2008)

There are few areas of public policy in which proposals to spend significant billions in public funds in aid of a nation-building project would not attract significant political scrutiny. The adoption of an interventionist regulatory framework targeted at a profitable, high technology sector of the economy would also seem ripe for political argument and conflict. Yet in New Zealand in early 2012, a settlement has been arrived at with planned government investment in broadband networks of \$1.5 billion, and a new regulator well embedded, with few political scars in sight for either of the two major parties that brought these changes about.

Far from these plans being the subject of substantive debate, the grand objective of accelerating the rollout of fibre-optic telecommunications networks to most of the population has been shared by both major political parties (New Zealand Labour Party, 2011; New Zealand National Party, 2011). New Zealand in recent years has witnessed a rising tide of state intervention in telecommunications markets. It has been evident in the regulatory and investing activities of government. It has been the same across governments led by both Labour and National. It confounds the expectations, held by some, of a convergence towards laissez-fair economic policy 
approaches in a world undergoing extensive globalisation (Fukuyama, 1992). It demands attention, understanding and further thought.

The purpose of this thesis is to outline changes in New Zealand telecommunications policy from 2000 to 2011, and to suggest some possible reasons for the triumph of a technocratic vision over the more competitive demands of conventional politics.

In this century, the ability to communicate, to share information and ideas, is integral to prospects for economic growth (Benkler, 2006). The rise of the Internet, the vast interconnected series of computer networks that gives people access to a huge array of information and services, has been one of the more significant changes to day-today life since it began to achieve mass take-up during the 1990s. The impact of the Internet on the economies of those states where adoption of it has become most widespread has been significant (Alcatel-Lucent, 2012), and over time, as the amount of data that can be transmitted over communications networks expands, the range of capabilities that people will be able to access at home and at work expands (Benkler, 2006).

Unlocking this potential requires modern infrastructure being in place that can support it. The refrigerated steamship opened new markets to New Zealand two centuries ago (Easton, 1997). High speed access to the Internet can do the same today. It is through telecommunications networks - the copper networks designed since the 1870s with the primary purpose of transmitting voice over circuits between handsets - that most people have accessed the Internet since mass adoption began. The physical limits these existing networks impose on the speed of data transfer restrict what people can do online. Large elements of many people's lives now rely on access to the Internet in a manner that would have been inconceivable twenty years ago. The higher speeds promised by new networks of fibre-optic cables are expected to allow the creation of even more applications, services and information that will lead in turn to further changes in people's lives (Alcatel-Lucent, 2012). Further opportunities for economic development will flow from this, as they have done so far with the current Internet. 
Around the world, governments have recognised the importance of this new infrastructure (International Telecommunications Union, 2010). Without any clear ideas of what services and applications will emerge, there are common plans to accelerate its rollout (OECD, 2008a). Countries show a sense that they are competing in the provision of digital infrastructure, hoping to entice high technology firms and talented people to their shores. Nobody wants to be left behind. Highspeed broadband networks based on fibre-optic technologies are arguably the next significant national infrastructure demanding the attention of policymakers (OECD, 2011). They may end up considered critical infrastructure, alongside earlier network infrastructures like the copper telephone network, networks of roads and rail, ports and airports and public transport, electricity and water distribution. These have all had huge effects on the lives of people in places they are available. It is a widely held view among policymakers that high speed Internet access through fibre-optic networks will join these earlier infrastructures as a profoundly significant determinant of the economic and social opportunities that citizens enjoy. The challenge countries face is one of timeliness, and of inducing large new investments in troubled economic times (OECD, 2008b).

As noted above, to provide faster access to the Internet requires the replacement of copper networks with fibre-optic networks. Copper telecommunications networks are extant investments with stable and evolving patterns of demand, and known prices in the market. Many were built with the assistance of public authorities, through funding and regulatory strategies that guaranteed the provision of ubiquitous access. They exist today and can be used for low speed broadband access, but the physics of data transmission through copper mean that the deployment of what is described today as ‘high-speed’ broadband is simply not possible.

Fibre-optic telecommunications networks, in contrast, are new investments, involving significant capital costs, with uncertain demand and revenue profiles (Network Strategies, 2008). They are being considered by private firms facing uncertain regulatory outlooks, and in a global economic environment that has made the financing of large investments more difficult than was the case in the past. The economics are made more difficult by very unclear demand scenarios for high-speed broadband - the full range of applications the service will be used for is not yet clear 
(Williams, 2011), and thus what value people will place on them or be willing to pay to use them.

Because not many of these networks are yet in existence (OECD, 2011), policy makers are learning as time proceeds what works and what does not to stimulate investment in and demand for these networks. There is thus little yet available by way of a policy template as to how to encourage such investment. In the absence of such policy initiatives, mass market service is unlikely to emerge in the short term (Network Strategies, 2008). The scenario resembles a classic welfare economics problem where public benefits from the availability of a service or infrastructure are greater than the private provider can capture, leading to inadequate or late supply. Like most such problems, technology is rarely the only factor involved. Politics, at least in the sense of who should be able to access high-speed broadband and when, is present too.

Governments that believe in the importance of high speed broadband infrastructure as a key requirement for ongoing economic development have therefore faced demands to adjust policy in ways that can facilitate these investments (TUANZ, 2008; InternetNZ, 2008), without losing sight of the need to encourage the competitive markets seen as essential to drive quality services, innovation and the best possible price. These demands, however, stand aside all the regular demands of politics: to differentiate, to propose a different approach, or to critique the objectives of those on the 'other side of the aisle'. The imperatives of development and of meeting the needs of the country - perceived or real - generate strong pressures for consistency and commonality (Katzenstein, 1985), as the case of broadband in New Zealand shows.

Each country has taken a different approach to how to roll out fibre-optic broadband networks. The focus of this thesis is New Zealand's recent history of policy change. From 2000 to 2011, the telecommunications landscape in New Zealand underwent fundamental changes (Howell, 2007; Moseby \& Purre, 2010). In 2000, the sector operated under general competition law with private companies providing services and infrastructure. In 2011, the sector had its own legislation regulating the behaviour of a range of firms, and the government had committed over $\$ 1.5$ billion 
to secure a timely transition to new fibre-optic networks that would be available within a decade to most New Zealanders, at home or at work. The changes mark a rising tide of state involvement in communications markets, a contrast with New Zealand's general laissez-faire approach, which demands attention in its own right.

If the scale of the policy changes involved is one factor making this case important, the curious lack of political debate the changes induced is another. Given the importance placed upon rolling this new network infrastructure out by governments and indeed by the public, why is it that there has been so little argument between the major political parties in the drive to obtain it? Investment of billions of dollars; choices about who will receive high-speed broadband service and who will not; the scheduling of rollout (who gets service when); opportunities for those areas and regions left out of the plans; the respective roles of the public and private sectors; the re-consideration of regulatory frameworks applying to the industry; the opportunities for rent-seeking; the response of incumbent firms and prospective investors to market and regulatory change and the demands to install infrastructure with unclear returns_-all of these would appear at face value to be intensely political issues. One might anticipate clashes and argument between the major political parties about who should win and who should lose. These issues are important but are in turn overshadowed by the most pointed question of all: whether the need (for high speed broadband) justifies any sort of government intervention at all, let alone intervention on the scale New Zealand has seen.

In New Zealand's case, such clashes have been notable mainly by their absence. Instead of hard-fought political battles over the fundamental questions, they have in fact been treated as settled. As a result, increased intervention has characterised the policy of both Labour and National. While there have been political disputes in the course of the rollout, and while some of these have been quite heated, they have largely focused on procedural aspects of policy decisions and the mechanisms chosen to achieve the goal of high-speed broadband rollout.

Political debate has not focused on the question at the heart of the matter: whether high speed broadband will provide such economic and social gains that the government should be involved in a range of ways to accelerate its provision and 
widen its reach. This convergence of programme despite the political differences the issue could have given rise to speaks to a unity of goal (ubiquitous, prompt access to high speed broadband) between two different political traditions that is on first consideration unexpected - but on reflection, less surprising.

Notwithstanding their stated philosophical distinctions, both the major parties have been proponents over time of a similar programme of liberal economic reform, when they were convinced that it was in the national interest to do so (Kelsey, 1997; Hazledine, 1998). The commonalities between the reforms of the fourth Labour and fourth National governments of the 1980s and 1990s are apparent: while they focused on different sectors, there was a consistent application of liberal market principles aimed at improving the efficiency of markets, and a concomitant reduction of the role of the state (Kelsey, 1997). This similarity has been a feature of New Zealand politics before: during the post-war period, both parties converged around a Keynesian welfare state policy paradigm and an economic approach focused on import substituting industrialisation (Easton, 1997).

In other words, and as has happened in the past in other policy areas, despite the opportunities for oppositional politics that the demands for high-speed broadband could have given rise to, similarity ruled the day. The prevalence of a coherent and shared economic vision between National and Labour - and the role of broadband in helping to realise it - meant that, as the case study to follow shows, politics was generally squeezed to the margins. A new convergence between the parties, on an interventionist approach to the delivery of important infrastructure, is apparent.

This convergence flies in the face of the mantra heard so often in New Zealand policy debates of the recent past, that 'freer markets' are the preferred approach (BusinessNZ, 2011). It also challenges the globalisation paradigm, which assumed that states would converge on a different equilibrium - one akin to the laissez-faire settlement of the earlier New Zealand debate (Fukuyama, 1992). It demonstrates, perhaps, that when it comes to the demands of capital in the modern era, the reality of the need for infrastructure provision wins out against philosophical preferences for a limited role for the state, especially when there is a broadly shared view that the market cannot provide what is required in the time period felt acceptable. 
The methodology employed in this case is an historical analysis, based primarily on published official sources and the knowledge of the author, and focused on a description of the key policy changes made. For intuitive clarity, the case is divided into two main domains: first, a consideration of the regulating activities of the state in New Zealand telecommunications markets, followed by a consideration of the investing activities of the state. The time period chosen, 2000 to 2011, covers the period from the instigation of a review that led to the first change from generic competition law regulation of the sector, to the general election that returned National to office for a second term and ensured that the implementation of the Ultra-Fast Broadband and Rural Broadband Initiatives would proceed.

It is important to emphasise what this research is not attempting to convey. Limitations of space mean that the focus is on the policy changes made, and the arguments made for and against them at the time insofar as these illuminate the case. There is no attempt to seek the opinions of decision makers as to the decisions that they made, or to conduct a textual or discourse analysis of the official paper trail leading up to each decision. The aim is to relate what has changed in New Zealand telecommunications policy, and to explain why debate between different approaches to the broader policy challenge was curiously absent.

The temptation to include a technical background chapter has also been resisted, at least in part because the technology is not the central focus of the case. The critical point is that fibre-optic networks are incommensurable with copper networks: they do not face practical bandwidth constraints and can be upgraded through changes to the transmission equipment used, rather than through the need for more or different cables in the ground. That is why the installation of such networks is seen as the next step in communications development: it will radically increase the capacity of networks, and ensure future upgrades are confined to the electronics powering the network, rather than creating a future need to install another set of cables into the ground.

In closing, the author by way of disclosure notes that as an employee of one of the advocacy groups mentioned in the course of the thesis, InternetNZ, he spent a 
considerable proportion of his professional time between 2005 and 2011 working on and advocating for an increased role of the state in broadband markets, on both the regulatory and investment axes. The case as presented and the analysis make clear that the advocacy sector had no great influence on the decisions of governments to become involved with broadband markets.

The main purpose of disclosing this connection is so the reader is aware that behind the cited material in the thesis is a breadth and depth of specialist subject knowledge, literature and experience that cannot easily be conveyed in the format of a thesis, but which has contributed to the author's knowledge, guided his analysis of and familiarity with the case, and interest in the subject. Our attention will now turn to the case, with the opening case chapter discussing the changing regulatory interventions of the New Zealand government in broadband markets from 2000. 


\section{Case Chapter 1: Intervention}

States and markets are intertwined (Vogel, 1996). Given the importance of markets in society, this comes as no surprise. Yet the New Zealand model of economic policy through the 1980s and early 1990s held that markets broadly operated best with the least possible intervention, part of the broader effort of liberal politics to reset the policy framework following the era of the Keynesian welfare state (Kelsey, 1997). The period 2000-2011 as shown in this chapter marks a change away from that liberal view. There were increasing levels of intervention in telecommunications markets, strengthening the role of the central state and creating a new sector regulator in telecommunications that accrued new powers as the decade went on (Patterson, 2011).

This chapter deals with the changes in regulatory interventions in New Zealand between 2000 and 2011. The trajectory is a clear one of increasing degrees of intervention. Until 2001, the telecommunications industry was subject to generic competition law only, the Commerce Act 1986. From 2001 to 2006, a light-handed industry specific regime was created by the Telecommunications Act 2001 (Howell, 2007). Significant amendments to that Act in 2006 expanded the powers of the regulator, required the operational separation of the incumbent copper network owner Telecom, and made some detailed changes to regulation that the previous phase had not achieved (Moseby \& Purre, 2010). From 2011 onwards, further significant changes to the Telecommunications Act were made to enable the structural separation of Telecom, and to put in place a new regulatory framework for the new fibre-optic networks that are discussed in the next chapter.

The chapter first discusses the basis of sector specific regulation in network industries. It then sets out the specific target of regulation relevant to the Internet: dealing with the problem of access to bottleneck facilities in copper telecommunications networks. It then considers each of the four main changes in market intervention. The 2001 Act, the 2004 unbundling decision, the 2006 Amendment Act, and the 2011 Amendment Act are each discussed. 
From 2000 to 2011, New Zealand has moved from an unusually 'arm’s-length’ approach to market regulation in telecommunications, through what arguably is the most radical and speedy set of regulatory changes in recent history, to a new situation where Telecom's structural separation is a matter of fact, and open access regulation is in place for the new fibre-optic networks. These significant changes, affecting large investments, would generally have been expected to give rise to significant political argument, given that they created winners and losers, and set a new direction for policy where there had previously been a broad consensus around the liberal approach to regulation. Changes to the regulatory framework could have a material impact on the wealth, of, for example, Telecom's owners - but also on the living standards of households in need of broadband services.

Instead, the level of substantive political conflict - about the overall objective to which these policy specifics were being applied - was relatively low. The 2001 changes to implement a light-handed sector regime, and the decision not to unbundle the copper local loop in 2004, occurred during the Labour government of 1999-2008, without serious dissent from National. The package of reforms in 2006, including the operational separation of Telecom, was more significant - but in the end almost every Member of Parliament voted for the amending legislation. The changes to allow for the structural separation of Telecom and the implementation of the new regulatory framework are the exception to this pattern, generating very strong political argument - but in the end the government retreated from the aspects of the legislation that caused the most conflict, leading to a reduction in the tensions as legislation proceeded immediately prior to the 2011 general election.

In a discussion of New Zealand telecommunications regulation, one element is notable by its absence in this treatment. The KiwiShare, an obligation imposed on Telecom at privatisation to maintain network coverage and a real-terms price freeze on line rental and local calling, was essentially a universal service obligation imposed on Telecom. It was a unique and much-remarked intervention with many effects (Howell, 2008). It was carried over into the new regime established in 2001, changing at that point from an unfunded obligation to a partly funded one (from industry levies set each year by the Commerce Commission), but forms no part of 
the consideration in the discussion which follows. This is because it was only aimed at voice communications, and while it continued through the 2000s, it has now largely been sidelined. The obligation to maintain provision is now shared between Telecom and Chorus (the separated network arm of Telecom following structural separation), but relates only to voice services. It is once again unfunded, and did not spur any substantive policy debate as to whether there should be any universal service requirements in the broadband market (Moseby \& Purre, 2010).

In essence and in closing these introductory remarks, regulatory interventions matter for two reasons. In the context of a discussion about broadband policy, telecommunications regulation is central. Most connections to the Internet in New Zealand are through copper or wireless communications networks operated by telecommunications companies. Their technologies, competitive situations, investment intentions and ability and incentive to offer better services to their customers are deeply connected to the way they are regulated. So, a story about broadband is a story about telecommunications in large part. It matters secondly because it was a clear example of a new, arguably more social democratic, government's first step away from existing liberal market regulation. Labour moved toward a different method of regulating what had come to be seen as a powerful monopoly. National continued that approach once in office after 2008. Consistent throughout was a curious lack of political conflict over the change in policy.

\section{Drivers for sector-specific regulation in network industries}

A wide range of interventions occur in markets, and not all are of interest to this research. The usual requirement of compliance with the legal framework applying to companies applies to telecommunications firms as it does to all businesses. The specific focus of this chapter is on regulatory interventions: those mandated by law that impinge only on the telecommunications industry. Such interventions typically require firms to do or not do things, to organise themselves in particular ways, or to offer services at given prices or on specific terms to other firms in the industry. 
While often based on competition law, sector specific regulatory interventions generally go beyond it in terms of the tools regulators have to address competition problems (Patterson, 2008). Generic competition law is based on the economic premise that competition drives innovation and efficiency, leading to an environment where prices are lowest and service best. In competitive markets with low barriers to entry, where the choices consumers make between diverse providers of similar goods minimise the market power of any given firm, overall welfare is improved (Monti, 2007).

Where industries do not enjoy these characteristics, the opportunity exists for firms to extract additional revenue from consumers over and above that which they could obtain in more competitive markets. The contemporary, liberal approach to the regulation of such industries aims to remove barriers inhibiting competition where this can be done. Where this does not suffice, access to bottleneck facilities is mandated to replicate as much as possible the conditions that would arise in a more competitive market. This is intended to transfer the gains the firms can enjoy from lack of competitive pressure to consumers, delivering lower prices and higher quality services. Only if none of these approaches are successful does the approach of directly mandating prices tend to be used (Cave, Majumdar, \& Vogelsang, 2002).

Regulatory interventions arise because of competition problems inherent in the nature of communications networks. Fixed line telecommunications infrastructure has monopoly characteristics due mainly to the following factors: the large scale of investment required to make widespread access to it available; the economic inefficiency of duplicating parts of such a network; the declining marginal costs traditionally associated with natural monopoly industries; and the network effects which increase the utility to each user of the network as more users join it (Varian \& Shapiro, 1999). These characteristics of the infrastructure create high barriers to entry for competitors, and thus give the owners of such infrastructure a significant degree of market (Cave, Majumdar, \& Vogelsang, 2002). Access to the parts of the network where such power is most concentrated is the core regulatory challenge, for reasons set out below. 


\section{The problem of bottlenecks - the regulatory target}

In telecommunications, insofar as the focus is broadband, the major competition problem is access to existing parts of an incumbent network that other firms cannot economically replicate (so-called 'bottleneck facilities') (Baldwin, Cave, \& Lodge, 2012). This access allows those competing firms direct access to a customer's premises from their own network, unmediated by the incumbent's network equipment. Historically, the prices charged by incumbents for interconnection between different networks for voice services (the ability for a person on one network to contact someone on another - for instance, a call between Vodafone and Telecom mobile phones) was a long-standing bottleneck access problem that could not be resolved under the Commerce Act framework (Tye \& Lapuerta, 1996). The focus on broadband means voice interconnection does not receive any further consideration.

This problem of access to bottleneck facilities is at the core of this chapter (Cave \& Doyle, 2007; Blankart, Knieps, \& Zenhausern, 2008; Vogelsang, 2003). Some parts of any given network are more replicable than others. A single high capacity cable that allows services to share information between Auckland and Wellington has a large market at each end, with many possible purchasers of services. Competing firms can afford to build their own nationwide networks between various points of presence, with larger firms having more points connected by their own infrastructure. Towards the edge of the network, however, the addressable market becomes smaller as high capacity cables split, and feeder cables from exchanges split further into cabinets (small street boxes where around 300 lines from premises are brought together in one place). At some point, the cost of replicating the incumbent's network is higher than the return that could be reasonably made from it once in place. Those parts of the network are deemed bottleneck facilities. For residential services, the bottleneck facility is generally the copper connection between an exchange (a building where several hundred or thousands of lines terminate to connect to the national network) and the household, anything from a few metres to a few kilometres long. This is generally referred to as the 'local loop' in what follows (Cave \& Doyle, 2007). 
The owners of bottleneck facilities have control of the connection between the household or premises and the exchange, which is the first point where a competing provider's network might be present. They have an ability to use control of the infrastructure in a range of ways that are detrimental to their competitors (for instance, slow fault repair; slow access to exchanges to maintain equipment), and an economic incentive to do so: to the extent that the network owners' services are superior to those of their competitors, they have an advantage in winning customers (Cave \& Doyle, 2007).

Tackling the problem of bottleneck facilities invites a range of approaches, all of which have been considered in New Zealand during the case study period. The traditional approach is the creation by the regulator of mandated service offerings, where prices and quality of service are determined by a third party, taking efficiency in all three forms (allocative, static and dynamic) into account (Blankart, Knieps, \& Zenhäusern, 2008) and using the pricing rules set out in the regulatory framework (in the New Zealand case, by Parliament) to determine reasonable access charges for competitors. A second approach is to mandate 'open access' to bottleneck facilities, the approach chosen as part of the most recent set of reforms in 2011. This requires the network provider to treat all customers (including potentially other parts of their own business) in the same way, without discrimination. A third approach is to deal with the ability and incentive to discriminate on the part of the integrated network owner/operator by separating, logically/functionally or in ownership terms, the control of the network from the services made available over it (Cave \& Doyle, 2007).

As the case study in the following pages shows, the trajectory has been towards greater intervention. If one considers a spectrum of intrusiveness, the least intrusive intervention in dealing with bottleneck facilities is to mandate non-discrimination. More intrusive is to dictate the terms of particular services and require these to be provided. More intrusive still is an obligation on the vertically integrated network company to split into its component parts - in a functional sense, or, at the zenith of intervention, by splitting ownership. New Zealand has reached the zenith and a 
mixture of all three remedies is now in place. The following sections show the evolution of this approach.

\section{First steps: the Telecommunications Act 2001}

In understanding the background to the development of the 2001 Act, the preceding history of market regulation needs to be briefly canvassed. Telecom New Zealand, the fixed line operator of telecommunications services in New Zealand, was corporatized in the 1980s, and then privatised in 1990 (Clear, an early competitor, had entered the market by this time). When it was privatised, the government made a decision not to implement a sector-specific regulatory regime, preferring to rely on generic competition law aside from the KiwiShare obligations discussed briefly above. The belief of the government at the time was that the best economic outcomes would be gained by applying competition law, in keeping with the conventional laissez-faire policy paradigm. It is also clear that there was no small gain to the final sale price the Crown received through the application of such a framework, and given the fiscal situation of the New Zealand government at the time this cannot have been anything other than an important consideration (Howell, 2007).

The Commerce Act 1986 prohibits anti-competitive practice by any company. In particular it prohibits any company from using market power in an uncompetitive manner. Yet there was, by the end of the 1990s, rising dissatisfaction with the ability of the Act to deal with the industry's competition problems (Boles de Boer \& Evans, 1996). Common complaints included the effects of long-running and slow litigation between communications providers, which was the only means to resolve any disputes between them. The nature of the regime (ex-post and with a Commerce Commission that could only seek the courts' decisions to impose financial or, in the worst cases, criminal penalties for anti-competitive behaviour) meant that remedies could only be found many years after anti-competitive behaviour had begun or occurred. For example the Clear-Telecom litigation on interconnection lasted from 1991 to 1994 (Tye \& Lapuerta, 1996), and litigation on aspects of number portability took over seven years 2000-2007, including appeals to the Privy Council, and 
resulted in a decision that was not expected by many observers upholding pricing rules that would limit the possibilities of competition emerging (Patterson, 2011).

Telecom's financial success during this period also added to concerns by some that the regulatory framework was not necessarily delivering the outcomes in competition terms that many anticipated. In the middle and late 1990s, the company's published profit was around \$700m per annum on turnover of around \$3bn per year (Telecom, 1998). Overall, the regulatory framework in this period was the product of the reforms of the 1980s and 1990s and by the end of the 1990s, the pressure for change had intensified to the point that an incoming Labour government had decided to inquire into the state of the market.

Labour's 1999 election victory was followed in February 2000 by the establishment of a Ministerial Inquiry into Telecommunications, headed by Hugh Fletcher, a New Zealand businessman (Moseby \& Purre, 2010). The Terms of Reference for the inquiry included some explanation of the rationale for it:

The world is experiencing a communications revolution. The Internet, eCommerce and other developments (including the convergence of communication technologies) are profoundly reshaping economic and social life. New Zealand must position itself to meet the challenge of this revolution. The development of information-based industries is a key to New Zealand's future social and economic development.

The telecommunications industry is of vital importance to the development of the information-based economy. New Zealanders and New Zealand businesses need access to cost efficient, timely and innovative telecommunications services.

Effective competition is widely seen as a key to the development of telecommunications services. The ability of new telecommunications networks to interconnect fairly and efficiently with existing networks is critical to the development of competition. (New Zealand Government, 2000a) 
In other words: broadband infrastructure was important, and the existing regulatory framework was seen as not delivering the conditions (competitive markets) that would aid in its creation. The government then defined its own objective for telecommunications regulatory framework to deliver:

The Government's objective for telecommunications is to ensure that the regulatory environment delivers cost efficient, timely, and innovative telecommunications services on an ongoing, fair and equitable basis to all existing and potential users. (New Zealand Government, 2000a)

The references to competition throughout these terms of reference demonstrate that the Inquiry was a reaction to the pervasive concerns with the Commerce Act's apparent inability to generate a competitive market in telecommunications. What was not apparent was the concern with changing market structures (in particular the later debate about the separation of the incumbent vertically integrated provider) that characterised the regulatory debate later in the decade. The specifics of the terms of reference in drawing attention to network interconnection, development of network capacity, KiwiShare obligations and other competition issues (New Zealand Government, 2000a) contribute to the Inquiry being seen as a reaction to the status quo and its complaints, and the concern that the status quo would not deliver the broadband infrastructure the government wished to see available in a timely way.

However other elements of the terms of reference show a different and more forward-looking focus for the Inquiry to consider if it chose to. The invitation to consider "relevant theoretical perspectives on best-practice regulation of the telecommunications industry”; “any factors specific to the New Zealand environment”; and “regulatory developments in other countries” (New Zealand Government, 2000a) showed that the government was at least in part aware that New Zealand's regulatory model might be a considerable degree outside what was mainstream - that is to say, sector specific regulation of telecommunications.

The Inquiry produced an issues paper that canvassed its terms of reference, accepted submissions from the public in response to this, and concluded with a final Report in 
September 2000 which set out its preferred changes to the existing regulatory framework and the rationale for them. In brief, the Inquiry believed a sector specific regime would be most appropriate for New Zealand because the evidence it had considered did not support the retention of the status quo (New Zealand Government, 2000b).

No doubt should be attached to this: the debate about whether change should occur was real and intense, not least due to the significant economic interests affected by the final decisions.

The Inquiry itself provides many of the arguments in favour of the changes it proposed as well as canvassing some of those against its proposals. Arguments for change in some respects are implicit in much of the above discussion. The existing model had led to an incumbent provider making very high profits (a source of satisfaction for Telecom and its shareholders, but a spur to reform for its competitors). The Commerce Act framework did not provide adequate restraints on anti-competitive conduct leading to those profits; without regulatory change this situation would continue. Absent reform, the outcome would be counter to that which the government sought in its objective for telecommunications regulatory policy's outcomes. Prices would remain high and in the absence of competitive threat, investment in infrastructure lower than would otherwise be the case (New Zealand Government, 2000b; Moseby \& Purre, 2010).

Remedies for uncompetitive behaviour were in the hands of generalist courts that were not specialists in the complex economic issues they were being asked to make decisions about, and would occur anyway so late in the piece that there was little point in taking action on the part of competing firms in the first place. Additionally, some of the remedies to competitive behaviour that other jurisdictions were beginning to employ - for example, unbundled local loops - were simply not available under a general competition law framework (Patterson, 2011). Remedies under the Commerce Act could not necessarily resolve the issues at stake.

Finally - the politics of the situation, created in part by the Inquiry and the evidence it obtained, created a platform for change. The platform was used by Labour, along 
with a populist tone, to tackle the problems created by a large monopoly whose transfer to the private sector had never been popular with the public.

After the Inquiry, the government moved to implement the broad thrust of the proposals it had made. The new Telecommunications Act 2001 was the cornerstone of the new regime, modelled on the draft Bill the Inquiry produced. It aimed to regulate the industry in "the interests of the long term benefits of end-users" (s. 18). It established a new sector-specific regulator, the Telecommunications Commissioner, responsible for the implementation of the framework set out in the Act. The Commissioner became a member of, and the Commissioner's staff was part of, the Commerce Commission, New Zealand's competition regulator.

The new Act set out specific service descriptions for regulated services, of which there were two types: specified services (where the regulator would be able to impose non-price terms like service quality requirements), and designated services, where the regulator could also set the price. 'Access seekers' (third party communications companies seeking access to the Telecom's network) could, where commercial negotiations had failed, ask the Commerce Commission to regulate conditions for access to these services on Telecom's network (Telecommunications Act 2001).

The Act also took account of the dynamism and rapid technological changes that are characteristic of the industry, by setting out procedures the Commissioner could use to investigate any emerging need for new services to be regulated if competition problems meant that regulation was advisable. A positive conclusion that new regulation was necessary would see the Commissioner making a recommendation to the Minister for the addition of new regulated services into the Act. The Minister's agreement was the final step required.

There were several noteworthy features of the regime established by this legislation. First, the Telecommunications Commissioner was not a fully independent regulator, a change from the recommendation of the Inquiry. The scheme of the Act meant that the final decisions regarding, for instance, the regulation of new services, were to be taken by the Minister of Communications and their cabinet colleagues, not the 
Commissioner (though on the latter's advice). There is a considerable body of literature on the benefits and costs of independent as against semi-independent regulators (Hausman \& Sidak, 2007), but that debate falls outside the focus here. Merits reviews, which allow the general courts to review the decisions of more independent regulators (for example the situation in the United States), were not included in the new regime - being more usual in circumstances where regulators are fully independent. Instead the Ministerial signoff in effect performed a similar review and consideration step once the regulator had reached its own conclusions (Howell, 2007).

Secondly, one of the more likely outcomes of the review could have been the full unbundling of Telecom's copper local loop, as had already occurred in a number of comparable jurisdictions by this time (for example the UK in 2000). The Act instead required the Commissioner to review the provision of wholesale services by Telecom and to inquire into the desirability or otherwise of such unbundling, with a report due later. This approach interacted with the first key characteristic noted - the lack of full regulator independence - to arguably lead to no unbundling in New Zealand in 2004, but that story will continue below.

Noteworthy was the politics of the reforms. While the former Minister of Communications, Hon Maurice Williamson, spoke against the legislation in initial parliamentary debates (Williamson, 2001), he indicated in the debate at first reading that National would be supporting it. But by the time the legislation reached third reading in December 2001, National members were stating they would oppose the legislation. The lead opposition speaker, Alec Neill, defined National's major concerns as being about mobile telephony issues (Neill, 2001) - outside the scope of this thesis. None of the contributions from the National members showed serious concerns with the appointment of an independent regulator or the light-handed nature of the regime in the Act. They did raise concerns about the legislation's mandating of a review of whether local loop unbundling should be implemented in New Zealand, and the general tone of contributions remained in the 1990s paradigm of opposing regulatory intervention as a matter of principle (Ryall, 2001). 
The opposition by National was not a major factor in public debate, other than the government attempting to draw attention to it during the 2002 general election campaign. It did not generate broad public opposition to the reforms. The legislation passed, and six years later the return of National to government did not see a de-regulatory approach resume. The Act marked a significant break with the status quo. A new regulator with a clear objective had been created to deal with competition problems in telecommunications. The Telecommunications Commissioner had the ability to impose new regulated services and tackle bottleneck problems in a manner not possible until that time (Patterson, 2011).

\section{Yes then No - The Local Loop Unbundling Review 2003-2004}

As mentioned above, the 2001 Act required the Telecommunications Commissioner to consider whether access to the unbundled local loop should be required, and the investigation began on schedule in 2003. Before this section considers that investigation, a brief outline of the nature of Telecom's network at the time is required.

In highly simplified form, Telecom's access network (that part of the network connecting premises to the core network) in 2003 was a set of telephone exchanges linked together by a national network. Each exchange was the centre of a web of copper wires which reach out to the individual premises and households within the local exchange area. The copper wires might be a single cable from exchange to door, or there might be street cabinets in between, but there was a continuous copper path from the exchange to the door (known as a metallic path). This was the conventional configuration of a voice telecommunications network, which was the original purpose of Telecom's infrastructure.

In the delivery of broadband services the main technology used over copper networks was (and remains) ADSL - asynchronous digital subscriber line. This is a technology that connects a broadband modem at the user's end of the line with a DSLAM (digital subscriber line access multiplexer) at the exchange, sending electronic frequencies along the copper metallic path to transmit and receive information (Papacharissi \& Zaks, 2006). It is asynchronous because more 
frequencies are allocated to the downstream (exchange to premises) channel than the upstream channel. Conventional ADSL connections in use during the period of the Commission's investigation had a theoretical maximum speed of around 7.6mbps (megabits per second) downstream, and about 1.6mbps upstream. These speeds represent the maximum speeds from premises to exchange - they do not represent the download speeds customers enjoyed, which depend on a whole range of factors beyond the exchange (Papacharissi \& Zaks, 2006).

DSLAMs were installed at the exchange and could support a number of end customers, typically 16 or 32 . They connected those broadband subscribers to the wider network, allowing people access to the Internet. Large urban exchanges provided service for up to 10,000-15,000 lines, so where there was a high density of broadband customers, there could be dozens or hundreds of DSLAMs installed to provide broadband services (Papacharissi \& Zaks, 2006).

In simple terms, 'unbundling' separates access to the copper phone line from the services provided over the line. It is a regulated requirement for Telecom to provide access to the line (the metallic path) from the local exchange to the premises to other telecommunications companies or ‘access seekers’ (Hausman \& Sidak, 2005). No longer would competitors be purchasing a wholesale service provided by Telecom's DSLAMs on Telecom's terms. Instead, access seekers would gain access to the exchange, to its 'racks' steel frames where they could install their own DSLAMs, access to electricity and cooling, and patch cables from the terminating point of the metallic path at the exchange to their own DSLAM device (Commerce Commission, 2007). All of these services would be available on terms and conditions set out in 'determinations' (legal decisions of the Commissioner under the Act), with designated services including price terms and specified services not including prices.

By giving access seekers direct access to the copper, they would then have complete control over the type and quality of service offered to their customers at the other end of the line, using their own electronics, maintaining their own billing relationships, deciding their own service standards, data packages, speed allowances and so on (Patterson, 2011). The assumption of the Act was that greater competition was desirable. The expectation was that unbundling would allow competing access 
seekers access to the same set of choices about services that Telecom had. This in turn was expected to lead to better services and lower prices for consumers. By encouraging access seekers to invest as deeply in the network as was economically feasible (that is, provide their own networks up to the exchange, and installing their own equipment at the exchange to reach beyond it on Telecom's copper to their customers), total investment would rise in the network, quality would improve and consumers would be better off (Cave, 2006). Because a DSLAM had a small number of ports relative to the number of customers accessible from an exchange, the economics of such investment were strong.

Unbundling was an open policy question when the Act was passed in 2001. Rather than deciding whether to proceed with it or not, the government decided to have the new regulator it had created examine the issue in detail and advise it of an appropriate approach. Section 64 of the Telecommunications Act 2001 (subsequently repealed) required the Commissioner to report within two years of its commencement on whether unbundled copper local loop should be a regulated service under the Act, with the review to commence at least twelve months after commencement. The process to be followed was the same as that set out in the Act for the Commissioner to follow if they were proposing a newly regulated service on their own initiative.

This clause's inclusion in the Act was a compromise between those who thought that unbundling should have been legislated for in the first instance, and those who did not think it was an acceptable remedy. Unbundling had been canvassed in some depth during the parliamentary debate on the legislation, when strong opinions had been shared on the question. Green Party MP Sue Kedgley called in Parliament for unbundling to be implemented immediately (Kedgley, 2001), while some National MPs described it as a failed remedy that had not delivered in other jurisdictions (Neill, 2001).

The Commission opened its investigation on 10 April 2003 with an issues paper. It published a draft report setting out its initial findings in September 2003, and an amended draft the following month taking account of new data for its cost-benefit 
calculations. The final report was issued on 22 December 2003 (Commerce Commission, 2003).

While the Commission's draft report from September recommended that the local loop be unbundled, the final report issued in December came to a different conclusion, and recommended that unbundling not proceed. Instead of mandating the unbundling of the local loop and the unconstrained access to the metallic path this would provide, it instead suggested the creation of a 'bitstream' product - a wholesale service from Telecom that used its own electronics on the copper loop, and which access seekers could use to provide broadband services (Commerce Commission, 2003). This is different in critical respects from unbundling: access seekers are using Telecom electronics and wholesaling that service, instead of using their own electronics. As such it required less investment, but also allowed less innovation, than unbundling would have demanded and allowed.

Not being a fully independent regulator, the Commission did not decide the issue alone. Its report made a recommendation to the Minister of Communications whose agreement was required for it to be upheld. In May 2004, after Cabinet consideration, he accepted the Commission's recommendation. This was not without controversy. Ministry of Economic Development advice had advocated returning the decision to the Commission for further consideration, as the Ministry considered that the Commission's conclusion was flawed, and that unbundling should proceed (Hammond, 2012). The length of time between the final report being lodged and the Cabinet's decision to accept it gives some indication of the debate within the government on the question.

The Minister of Communications was unable to persuade the Cabinet to make a decision that was contrary to the Commissioner's recommendation, and so the creation of the bitstream service was agreed to instead of local loop unbundling (Swain, 2004). The Minister did however extract a range of commitments from Telecom around the time the decision was made, one of which was to prove important in future: Telecom agreed, according to the government, that in aid of developing a more competitive market for broadband it would target $30 \%$ of broadband connections being wholesale - that is, provided by competitors - within 
eighteen months. According to Telecom, the agreement was that $30 \%$ of new broadband connections would be wholesale (Moseby \& Purre, 2010). This difference of view is discussed further below.

The implications of the decision not to unbundle the local loop in 2004 are telling. New Zealand's experience once unbundling was implemented shows that, at the right price point, it is a driver of serious increases in broadband uptake and decreases of the price of broadband services. The bitstream option that ended up being adopted did not deliver that outcome (Patterson, 2011). Along with the failure by Telecom to meet the commitment it made to the government regarding more competitive provision of broadband connections around the time that the decision was being made, the absence of local loop unbundling helped to create the pressure for change that led to the much stronger regulatory interventions contained in the Telecommunications Amendment Act 2006. That intensification of regulatory intervention was announced only two years after the Minister accepted the bitstream decision discussed here, in May 2006.

Given subsequent developments, some market participants have lamented the 2003 report and the 2004 decision as a missed opportunity: had unbundling been required in 2004, and implemented in 2005, competing ISPs would not have had the problems caused by the cabinetisation programme and would have been able to develop a broader range of services faster, leaving a more robust market in place today. It may have even been the case that with higher investment and more competition in the copper network, there would have been less pressure on governments to make the investments involved in rolling out a fibre-optic network (the subject of the next chapter).

Ironically too, had Telecom not been so effective in lobbying against unbundling in 2003/04 (Telecom, 2003), it may not have faced the more stringent regulatory settlement that was later imposed upon it. These changes cost the company the ability to control its own network assets, an ability it has been unable to regain. 


\section{The Telecommunications Stocktake, and the 2006}

\section{Telecommunications Amendment Act}

The focus of this section is on the major changes that occurred in 2006 to the Telecommunications Act 2001. The government through the Ministry of Economic Development had been conducting a review of the 2001 legislation in 2005, the Implementation Review of the Telecommunications Act (New Zealand Government, 2004b), and during 2005 Hon David Cunliffe (appointed to the full Communications portfolio in December 2004) called for sector input about the state of the sector, which he labelled a 'Stocktake'. For simplicity, the Stocktake and the Implementation Review, though separate processes, are generally treated interchangeably in what follows. Their conclusions joined in any case in decisions made and announced in 2006.

It is difficult to overstate the significance of the 2006 legislation. It restructured the telecommunications industry more radically than the government intended at the beginning of the process (Howell, 2007; Patterson, 2011). The scale of change was akin to that imposed on the energy distribution sector in the late 1990s, though, due to the faster changing nature of the telecommunications industry, it is not clear which set of changes was more disruptive.

In canvassing the changes made in 2006, a preliminary discussion of changing conceptions of how to regulate telecommunications is required. One of the significant debates that came through in the Stocktake and the 2006 Amendment Act was a shift from trying to affect the decisions of the vertically integrated telecommunications carrier through the mandating of particular services as discussed at the beginning of this chapter, to unbundling the network from the services provided over it.

The approach implemented in 2001, while similar to that in most other jurisdictions at the time, had limitations. Remedies were slow, the framework was costly for regulators and for carriers, and the whole approach was a reactive way to try and improve the competitive situation. A view was established by the time of the Stocktake that, as set out in the 2001 legislation, these remedies were not working 
(Patterson, 2011). The earlier discussion in this chapter about the ability and incentive to discriminate began to filter through into the public debate. A range of different forms of discrimination were observed in the market, and competing access seekers were making their complaints heard.

Discrimination could not be avoided by the type of regulation in the 2001 legislation (Cave \& Doyle, 2007). Discrimination per se was not the particular problem it had set out to solve. No level of detail or instructions as to how a service should be provided to access seekers could solve the discrimination problem. The incumbent carrier could discriminate, knowing that it would take time for competitors to notice it. It would then take time for regulators to understand their discrimination, work out services or penalties to punish the behaviour or prevent its recurrence, and so on (Patterson, 2008). Thus, the regulatory argument moved to a different focus. If the competition issues created by vertical integration and the existence of bottleneck assets could not be resolved by designating particular services delivered in particular ways, perhaps it was time to take new approaches. Unbundling was a remedy in this area, but further considerations were now at play. Instead of accepting the integrated market and trying to clean up the consequences, perhaps it was time instead to disintegrate the market, and change the incentives driving the behaviour of the incumbent operators (Cave, 2006).

A vertically integrated carrier operates the physical infrastructure of the telecommunications network. It provides wholesale services as inputs to other parties' desire to provide retail telecommunications services. And it provides such retail services itself to members of the public. There are conceptual boundaries between these various activities, as well as real boundaries (Cave \& Doyle, 2007) certainly the distinction between selling a service to an end consumer and selling a service to another firm as an input to an end consumer is clear, as is the distinction between operating a network infrastructure and selling services which use it at a wholesale or retail level.

The logic behind the vertical integration of the firm across all these activities is varied (Howell, Meade, \& O'Connor, 2009). One argument is that the transactional costs (generated by the need to maintain contracts and arms-length relationships 
between different divisions) saved by doing so are considerable when all the activities involved in operating a network are controlled by a single firm compared with an alternative, more separated firm structure. Another argument is that the investments in such a network could only be sustained with the level of demand provided by the wholesale and retail arms of the company making the investment - a desire, in other words, to control and gain income from as large a section of the value chain and as large a share of the customer base of the industry as possible. A more subtle argument is that, in the absence of the information about consumer preferences and demand that comes from retail (and to a lesser degree wholesale) operations, a separated network company could not make optimal decisions about what to invest in or when.

This vertically integrated model conflicts with a desire to develop more competitive wholesale and retail markets by providing access seekers with effective access to bottleneck facilities (Cave \& Doyle, 2007). Discrimination was an inevitable outcome, according to the critics, of the way the industry was structured. Such firms had the ability to discriminate due to their control of the bottlenecks, and the incentive to do so because of the economic rewards they would reap. Instead of trying to correct the consequences of a vertically integrated industry structure, the debate shifted: it was time to change the structure itself.

A range of approaches was available (Crandall, Eisenach, \& Litan, 2010). The most intrusive possible such change was called 'structural separation'. The telecommunications network would be divested by the integrated company, and placed in separate ownership. It would make access to its network available to any access seeker (not owned or controlled by it) wishing to use it. Its incentives would be to maximise revenue by maximising the number of customers attached to the network, and investing in network technology and coverage to increase the size of the market it could serve, and improve the quality of the services it could offer and thus the prices it could charge for them. Often the separation of the network assets under structural separation is complemented by the separation also of the wholesale and retail operations of the company on the same basis: a wholesaler would have no ability or incentive to discriminate between different retail providers of services. 
Such an approach, changing the market structure, faced two significant criticisms. It had never been attempted in any actually existing comparable telecommunications market, and a related approach imposed on the New Zealand electricity distribution markets (and which provided lessons to those developing the policy) in the latter part of the 1990s had not delivered many obvious gains - but had driven obvious costs (Howell, Meade, \& O'Connor, 2009). So there was not the opportunity to consider lessons learned by others in taking such an approach: New Zealand would have been conducting an experiment with an important piece of national economic infrastructure.

The second criticism of structural separation in the 2005-06 debates was that it would be an unprecedented interference in the property rights of the owners of the network (New Zealand Business Roundtable, 2006). Reasonable investors, while warned in every Telecom share prospectus of the risk of future regulation of the network, would have been unlikely to anticipate a government mandated separation of the investment they had made into different entities. The requirement of separate ownership could have been reached with a new series of share distributions to existing owners, but troublesome questions regarding the distribution of existing assets, income streams, investment plans and so on - all in the face of determined opposition by the Telecom board and management - would have rendered the picture extremely complex.

Nonetheless, the policy arguments in favour of moving towards a more ex-ante regulatory framework along the lines discussed above ended up being persuasive to the government. The process began, as mentioned, with a Stocktake of the current environment. David Cunliffe, the Minister of Communications, initiated the Stocktake as a review of the telecommunications sector before the 2005 election, making it public after the poll. The purpose of the Stocktake was set out in a press release from the Minister at the time of the announcement of its conclusions:

[t]o consider developments in the telecommunications sector as a whole over the medium term (three to five years). While a primary focus has been placed on the broadband market and broadband performance as a factor in 
economic performance, the review has had regard to the overall performance of the telecommunications sector. (Cunliffe, 2006c)

'Stocktake' was an interesting phrase to use. The process was largely informal, with internal Ministry of Economic Development policy staff used, reports from consultants obtained, a public call for input, the direct (indeed on some occasions by the Minister himself) solicitation of submissions from a range of interested parties (industry participants, lobbying and advocacy organisations and so on), and ending with a Cabinet process to determine the results (Moseby \& Purre, 2010). A broader approach, such as the external and more independent review that the Commerce Commission conducted in respect of unbundling, was not chosen. The external advice that played a role in the process came from two sources, as mentioned above: from consultants working to briefs provided by Ministry of Economic Development staff, and from members of the public and other organisations who lodged submissions.

The key themes which came through in the course of the Stocktake was that to deliver the government's intended objectives, further regulatory reform would be required. The ISPs dependent on access to Telecom's network had many complaints about the sorts of services they had access to, Telecom's performance in delivering them, and the generally hostile attitude that the company exhibited towards competitors (ISPANZ, 2006). Most of the submissions from those groups argued that the earlier decision not to unbundle Telecom's copper local loop had been the wrong one, and needed to be reconsidered. Others went further. InternetNZ called for the full structural separation of Telecom, with separation of the ownership of the network from ownership of the retail business (InternetNZ, 2006a).

Notable in the public submissions is the breadth of the coalition of interests calling for further regulatory intervention, and the thinness of defenders of the status quo. Telecom obviously defended the status quo, but no other significant submissions did. Public comment in a range of media were pushing in the same direction as the majority of submissions, and the government itself had clearly expressed the likely need for change given the state of the market outlined earlier in this chapter, and the very clear hints in the language setting out the Stocktake’s purpose. 
A further impetus for change lay in the government's view that Telecom had not met its agreed commitment to ensure that $30 \%$ of broadband connections would be wholesale by the end of 2005. That concern almost overrode the concern the government had that New Zealand broadband penetration remained unimpressive compared with other OECD countries - indeed, the country's place in the broadband league table had declined from $16^{\text {th }}$ in 2001 to $22^{\text {nd }}$ in 2005 (InternetNZ, 2006a). Telecom's failure to meet those targets provided government with internal justification of why change might be required. Telecom interpreted its commitment as being that $30 \%$ of new broadband connections would be wholesaled. The government's interpretation was that it would be $30 \%$ of all connections. There was a significant difference in the number involved - and as a proxy for competition, this disagreement left the government convinced that the existing regime would not drive the competition it desired (Moseby \& Purre, 2010).

The Stocktake in fact came to a sudden - indeed abrupt - conclusion. The government had signalled its intention to announce decisions regarding the outcomes of the review as part of Budget 2006, scheduled for 18 May 2006. However, a full release of the government's plans occurred early due to an unauthorised leak of the preliminary version of the final Cabinet paper setting out the reforms to a Telecom executive the day prior by a Messenger from the Parliamentary Service (Moseby \& Purre, 2010). As soon as the company realised the import of the information it had received, and given its obligation to disclose material information to the public or otherwise be at risk of breaching insider trading rules, it informed the Minister and the decisions were publicly announced the next day, 3 May 2006. Most of the changes mandated by the Stocktake were to be implemented by means of amendments to the Telecommunications Act 2001, to which the next part of this section addresses itself.

The conclusions of the Stocktake and the background review of the Act, as set out in the Cabinet paper released on 3 May (New Zealand Government, 2006) were that the existing regulatory framework was not adequate to the delivery of the fast broadband services the government now wished to see available to New Zealanders. The reasonably light touch approach set out in 2001 would be supplemented with 
enhanced powers for the Telecommunications Commissioner, enabling them to solve several blockages with the framework the 2001 Act had established. In doing this, the regulator would remain semi-independent, with Ministers still making final decisions on key issues on the Commissioner's advice. The focus of the changes also remained regulatory. While the pendulum had swung further in the direction of regulation, there remained further room for travel.

Cabinet's decisions regarding the regulatory framework were turned into legislation that became the Telecommunications Amendment Act 2006. The bill as introduced closely matched the decisions in the cabinet paper so this section first canvasses those decisions, and then describes the changes made in the course of the legislative process, and summarises the regime as established when the Act was passed in December 2006.

Before detailing the changes, the importance of timeliness needs to be stressed. Telecommunications, compared with other network industries one might typically think of (roading, rail, water, air travel, shipping), is fast-changing. Technological developments occur at rapid rates, and while the physical infrastructure of the access network has been copper-based for a large part of the past hundred years (and is only beginning to be superseded by fibre-optic cable now), the uses made of that copper path have developed quickly. As an example the forms of ADSL available have progressed from ADSL, to ASDL2, to ADSL2+, to VDSL, to VDSL+ in the course of the past ten years, each offering improved broadband speeds (Papacharissi \& Zaks, 2006). The important point to draw is that slow-moving regulatory processes can assist in the acquisition and retention of market power by a dominant firm. If a new service is likely to be superseded within three years, and it takes two years for other market participants to gain access to it, then they are in a disadvantaged position - they cannot offer comparable services, and so will be squeezed out of the market. This timing dimension is crucial.

The major changes arising from the Stocktake and the implementation review (some of the decisions on the latter had been made in August 2005 but had not yet moved to implementation (New Zealand Government, 2006)) were fourfold. The first change was important in the medium term. After the 2001 changes, where a service 
was specified in the Act's schedules, access providers and access seekers were expected to negotiate commercial terms for price and non price matters to allow use of that service. If terms could not be reached, the access seeker could seek a determination by the Commissioner that would set out non-price (and for some services, price) terms for access to that service. This process would typically take between six and twelve months, and would result in an access determination that required those terms to be available to that access seeker within a specified time period. In practice, Telecom generally made available the same terms to all other access seekers simultaneously and on the same timetable as it made them available to the access seeker named in the determination, but it is important to note that it was not obliged to do so.

The process was slow, it could only be initiated by complaint (requiring the access seeker to expend funds and human resources to manage the complaint), and only guaranteed improved access to the access seeker/s party to the determination. Further, a complaint leading to a determination could only be made after commercial negotiations had been attempted, and this was able to be used in a fashion that could slow the process even further. The process was expensive and indeed, only the largest access seeker, TelstraClear, ever sought Commission investigations under the 2001 framework (for interconnection in 2002 and for bitstream in 2005).

With the changes proposed, the Commission could, on its own judgement and on its own timetable, choose to commence what was now called a Standard Terms Determination (STD) process. This would set out non-price (and for some services, price) terms for access to a particular service that any relevant access seeker could make use of. There was no longer any obligation on access seekers to attempt to negotiate commercial solutions with Telecom prior to the process, and the Commission could manage its STD process in a fashion that matched the market's development rather than lagging far behind it.

Secondly, a revised information disclosure regime was implemented, centred on accounting separation. The discussion in a previous section regarding the thrust to move to ex-ante rather than ex-post regulation canvassed issues of market structure. One can consider a spectrum of interventions designed to shape the market structure 
in a vertically disintermediating sense (that is, reducing the influence of an infrastructure provider on a downstream service provider). From information disclosure at one end, through more prescriptive accounting separation, to a functional or operational separation of network and services, to full structural separation at the other, a range of alternatives was available.

Accounting separation was the choice set out in the Cabinet's proposals. It was a tentative step towards a different approach but it did signal the government had considered the issue, and was prepared to go some way towards a new approach. In 2010, the Commerce Commission published its analysis of the first set of interim regulatory accounts, for the 2008/09 year (Commerce Commission, 2010). While these were produced later than they would have been without the changes to be discussed below, they were at the time seen as an improvement on the status quo.

The third of the major changes was the ability of the Commission to accept binding undertakings from access providers regarding the services they would make available, in lieu of regulation. The policy intention behind this change was to allow for the expeditious solution of some regulatory challenges where the access provider was prepared to make a reasonable offer. Undertakings would not require a determinations process, saving six to twelve months and allowing the regulatory framework to be more responsive to the needs of the market. A modified version of this power ended up being used in the operational separation process discussed below, but otherwise it has not achieved widespread use.

Fourth of the major changes was an acknowledgment that the earlier decision not to unbundle the local loop was the wrong one. Local loop unbundling would now be made available, and the other related services required to operate it would also be regulated for (access to physical facilities, collocation of equipment and so on). This was the policy change of most interest to the competing ISPs, and was seen by the government as a natural way to assist companies move up the 'ladder of investment' - that is, to use access to wholesale products to build scale, and then invest in their own equipment and make use only of the pure network access provided by local loop unbundling (Cave, 2006). 
This set of proposed changes along with the other detail presented in the Cabinet paper amounted to a major intensification of regulatory pressure on Telecom, and came as a major surprise to the company from its response. The author was present at a breakfast meeting on 3 May in Auckland, the day the news was made public, and a Telecom executive asserted there that no government would be "so stupid" as to impose the sorts of legislative remedies which the company was, by then, already aware were about to be announced.

Telecom had been able to fend off aspects of this pressure in the 2004 unbundling proceedings but had failed in the government's opinion to deliver the outcomes it had promised, and so in 2006 the picture changed. In particular, the government's interpretation of Telecom's commitment regarding wholesale broadband connections was instrumental in changing Cabinet's mind and encouraging it to view the earlier reforms as not delivering what had been promised. As a rule, governments do not appreciate large companies not following through on promises they have made.

The debates around the Select Committee process also demonstrated pressure for more, not less, change than set out in the government's initial proposals. The government had invited the committee to consider what measures of separation would be advisable beyond the accounting separation it had included in the draft legislation, explicitly referencing operational and structural separation (New Zealand Government, 2006). While ISPs argued strongly in favour of the unbundling changes (ISPANZ, 2006), the conceptual debate about using the legislation as an opportunity to go much further along the spectrum towards structural separation of Telecom were taken by many. InternetNZ, for example, submitted that operational or functional separation of Telecom should be mandated by the legislation, and that it should also provide for the possibility of future structural separation (InternetNZ, 2006b).

In InternetNZ's eyes, and those of many commentators (TUANZ, 2006), the history of private ownership of Telecom had provided ample evidence of the failure of expost, general competition regulation to tackle the market power that the company enjoyed. The acknowledgement of that in the 2001 changes, the consideration but deferral in 2004 of unbundling, and the expansion of regulatory pressure in the initial proposals showed that government accepted there was a problem which would not be 
solved by the status quo - shown by the relative decline rather than improvement in broadband uptake compared with that in other countries mentioned above. The question then was whether more intense ex-post regulation could deliver, or whether changes to the market structure that would reduce Telecom's ability or incentive to discriminate against third party access seekers would lead to better outcomes.

In the end, the latter was the outcome chosen by the Select Committee, accepted by the government and enacted by Parliament. The fundamental change to the proposals between their announcement in May and their legislative conclusion in December was the addition of a new part to the Act mandating the operational separation of Telecom. A plan to be agreed between the company and the minister would provide for a three-way split of Telecom into network, wholesale and retail divisions, similar to that imposed on British Telecom in the UK in 2005. A phased programme over a number of years would allow the transition to occur in a coherent fashion.

Alongside the undertakings implementing operational separation (Telecom, 2008), Telecom further agreed to roll out new infrastructure to a given proportion of the population through investment in a ‘cabinetisation' programme - pushing the reach of its core fibre-optic network out to cabinets in urban areas to allow the delivery of much faster broadband services (AAS, 2008). This rolled out in the 2007-2010 period, and involved a commitment by Telecom to invest $\$ 1.4$ billion in the new infrastructure rollout. The outcome was presented by the government and by Telecom as a win for both: a newly independent network unit (named Chorus) would have a high speed broadband network in place to deliver improved services to New Zealanders (Moseby \& Purre, 2010).

In securing this outcome, the government ended up with a broad political consensus. Of the four sets of regulatory interventions analysed in this chapter, the lack of political opposition to the changes was most evident in this case. By not including proposals for operational separation in the draft legislation, the government appeared to present a solution to the problem most widely criticised - the lack of local loop unbundling. It knew, from its own review and from submissions during the Stocktake, that there was pressure for more intrusive regulatory measures. By allowing these to emerge during the legislative process and following the testimony 
of so many in support of further change, the government put the opposition in a difficult situation: it would have had to oppose a strong public push for further change in order to support Telecom, where (consistent with its broad approach to the 2001 legislation) its instincts may have lain. In the event, the National Party and all opposition parties other than ACT voted for the legislation at third reading, meaning it passed into law with 118 votes in favour, and 2 votes against.

One consequence of the separation deal, however, was poorly understood at the time. The economic impact of unbundling, as earlier described, relied on the aggregation of metallic paths or unbundled local loops at exchanges around the country. Each exchange had a large number of lines terminating at it, and each DSLAM had a small number of ports. The incremental investment for access seekers to provide service to new customers was limited, and the number of sites which they would have to have access to was also limited - in a practical sense to the 50 or 100 largest metropolitan exchanges where they might wish to offer services.

Cabinetisation changed this entirely (AAS, 2008). Where a cabinet is installed and fed by a fibre-optic cable, there is no metallic path from the premises to the exchange. Copper stops at the cabinet. This shorter length of copper loop is the reason that the new configuration allows faster broadband speeds. But consider the implication in light of the previous paragraph: competing service providers would not be able to address many thousands of customers from an exchange. They would instead have to install DSLAMs at each cabinet. 3,600 additional, fibre-optic linked cabinets were to be installed. Each cabinet provided service to 200-300 premises only. In 2006 only approximately 15\% of premises had broadband. Investing in DSLAMS in thousands of cabinets could not make economic sense, and has not made economic sense: at the time of submission of this thesis, there was no 'subloop unbundling' in progress (the regulated service similar to local loop unbundling, allowing access seekers to install plant in cabinets and offer services along that metallic path to the premises).

While this meant faster services for the public, it impeded the approach set out in the 'ladder of investment'. The promise of unbundling as a foundation for the ladder of investment was never entirely realised. Even as unbundling became available and 
was taken up in some urban exchanges, it was being superseded by the cabinetisation programme. The chilling effect of this helps to explain both the small scale of alternative ISPs in New Zealand, and the low number of unbundled lines in New Zealand as a proportion of all lines, compared with those in other jurisdictions (AAS, 2008). On the other side of the equation, New Zealand consumers of telecommunication services clearly have access to better services than they would have done without Telecom's cabinetisation plan.

That set aside, the new regime has broadly been considered a success (Patterson, 2011). The Telecommunications Commissioner conducted the STD process in 20072009, granting cost-based access to the local loop, to sub loops, and to the ancilliary services that allow these to operate. Telecom's operational separation was completed in 2009-10 (and has since been superseded with full structural separation) with Chorus widely regarded as taking a different approach to its commercial relationships with other access seekers and attempting to treat other Telecom business units the same as it treats external access seekers. The cabinetisation process is complete and has been making higher speed services available to people inside the footprint covered by it. The first set of accounting reports under the information disclosure regime have been produced for 2009/2010, though the information disclosure regime was changed in 2011, meaning that future information will be different.

Overall, the reforms in 2006 led to the adoption of a regulatory framework delivering on the stated outcomes sought by government. New Zealand's framework was now very similar to that applying in other countries, including the UK. Services were better than they had been and more widely available than before. Costs were lower than they have been.

\section{Telecommunications (TSO, Broadband and Other Matters)} Amendment Act 2011

The fourth set of changes to telecommunications law considered in this chapter relate mainly to the Ultra Fast Broadband and Rural Broadband Initiatives, policies 
introduced by the National Government that came to office in November 2008. Both programmes are investment programmes, and they are considered in detail in the following chapter. The discussion of regulatory matters in these initiatives can only be understood with reference to the broader set of changes, but it does form part of the story of market intervention and so is included here for completeness.

For context, the purpose of the Ultra-Fast Broadband Initiative was to roll out fibreto-the-premises networks to $75 \%$ of New Zealanders, by means of a public private investment partnership between the Crown and interested investors (Key, 2008). Local Fibre Companies or LFCs would invest in fibre-optic network infrastructure. They would be barred from lighting the fibre-optic cables, or serving retail customers: they would simply provide the expensive physical infrastructure which competing firms would use to deliver services to the public. The Rural Broadband Initiative was designed to provide improved broadband services in rural areas through grants paid to telecommunications providers, financed mainly by an industry levy but also with some funds from taxpayers (Joyce, 2010a).

In agreeing investment partners, the major partner for the UFB rollout was Telecom's network arm Chorus. The RBI rollout was granted to a joint bid agreed between Telecom and Vodafone. Broadly speaking, the rural initiative remains subject to the ordinary application of the Telecommunications Act 2001; it is in the Ultra Fast Broadband Initiative that considerable innovations occurred in regulation, though these ended up being less extensive than initially proposed by the Government. This is the focus of this section.

The initial UFB documentation outlining the invitation for parties to participate in the partner selection process or 'ITP' (New Zealand Government, 2009) provided that they would be contractually obliged to agree, in advance, the per-connection cost they would charge to service providers for access to the fibre-optic infrastructure. These price terms would be set for up to ten years. The ITP also specified open access requirements, obligations that would require the LFC to provide neutral and equivalent access to its services to all comers, not attempting to tilt the market in favour of any particular wholesale provider. 
This amounted, in effect, to an attempt to decide key terms by contract, rather than having such matters being generally determined by the sector's regulator as had been the case in the copper world. It was a controversial and distinctive part of the initial plan. While the Commerce Commission under the Telecommunications Act 2001 would retain oversight of the sector, including the new networks, it would have no immediate direct role in regulating them. After the period of the initial contracts, the market participants would face the general framework created by the Act. If the Commission felt that concerns were emerging that the contracts with LFCs had not addressed, it had recourse to the normal process under the Act to commence regulatory interventions. It was felt that competition with the copper access network, which would remain regulated, would provide a constraint on any abuses that LFCs may have been inclined to attempt within the contracts they agreed with the new investor, Crown Fibre Holdings.

To manage this public investment, the Government established a new agency: Crown Fibre Holdings Limited (CFH). CFH was established to be the lead agency in managing the public investment involved in the scheme: defining the contracting process, the technical and operational requirements for the LFCs, the business requirements for their own structure and for their interactions with other market participants, and the sequence and timetable of the rollout. They were established within the Ministry of Economic Development at the end of 2009, and slowly took over responsibility for the rollout of the scheme through 2010.

This description, anodyne as it is, hints at a few of the difficult dilemmas CFH faced. Chief among these is the clash between its role as investor, and as regulator. As the investment manager on the public's behalf, it has an incentive to maximise the rollout of broadband infrastructure for a given sum of investment - to drive hard bargains to get the best value for money for taxpayers. As already mentioned above, however, $\mathrm{CFH}$ is also the author of the contracts that were to have provided for the contract-based regulation of the price- and non-price terms that LFCs are able to offer. Concerns about this dual role have been expressed as recently as February 2012 (TCF, 2012). 
This is a conflict that was created by the government's initial decision to avoid an up-front role for the Commerce Commission as regulator. If CFH relaxed some of the requirements it imposed on the LFCs in order to maximise short-term investment decisions by LFC partners, it would risk creating a market structure that did not measure up to the potential for a newly competitive landscape for service provision over the new fibre-optic infrastructure. This risk was compounded by the fact that any trade-offs would be made behind closed doors, due to the commercial-inconfidence nature of the negotiation process between CFH and intending LFC partners.

It is difficult to understand why the government decided to put CFH in this position. It was one of the original arguments for the privatisation of state-owned telecommunications companies in the 1980s and 1990s that the conflict for government between its ownership interest in such companies, and its regulatory role in assisting with the development of a more competitive telecommunications market, meant that the clash should be avoided - at that time, by selling its interests in telcos (Bortolotti, D'Souza, Fantini, \& Megginson, 2002). This argument was heard repeatedly in the process of governments divesting themselves of ownership stakes in conventional telcos, not least relevantly with the privatisation process for Telstra (King \& Pitchford, 1998).

It is beyond the scope of this thesis to consider whether the evolution towards more competitive regulatory frameworks for telecommunications was made easier by the ending of that conflict (it definitely followed rather than led privatisation efforts), but a wider treatment would consider that question. To be re-investing in telecommunications infrastructure would recreate that prospective clash of interests for the government in and of itself. To be doing so, while simultaneously maintaining in government hands the decisions about how to regulate that investment, is a significant change to the framework. It is also a significant change in the independent role that the Commerce Commission had begun to win for itself in the telecommunications industry since passage of the Telecommunications Act 2001.

A second key dilemma for CFH was the responsibility it faced for selecting partners in a very difficult strategic and tactical environment. As already mentioned, the role 
of Telecom was a key problem for the company. Telecom was at the time in the midst of several processes that made its ability to respond coherently to $\mathrm{CFH}$ difficult. It was conducting a $\$ 1.4 \mathrm{bn}$ rollout of a fibre-to-the-node network to allow its copper premises networks to support faster broadband services. It also faced ongoing pressure from the operational separation process to build a business fit for competitive markets. Finally, it was also initially barred from participating as a controlling partner in the LFC model (New Zealand Government, 2009), but was simultaneously (due to its dominance in downstream services markets) critical to the success or otherwise of the scheme.

More sharply, if Telecom customers did not make use of the LFC fibre investments, the economic viability of the new fibre-optic networks would be seriously compromised. Yet, if a vertically integrated Telecom could participate in the scheme, then the chances of achieving the government's ambitions of creating a new vertically separated market would have been undermined before they had even begun. This dilemma, along with clear unwillingness by the government to change the core components of the scheme's approach, led to suggestions from within Telecom from early in 2010 that it was beginning to consider a structural separation of its network assets from its retail business. Telecom's chief executive, Paul Reynolds, suggested an approach that would see new shares issued to split the ownership, during investor briefings in May 2010 (McBeth, 2010). Such an approach would turn Telecom into a valid participant in the scheme.

The structural separation of Telecom, and the resulting network operator's potential for participation in the scheme would be welcome prospects from many perspectives. Besides allowing the participation of the incumbent in the scheme, it would mean that Telecom's customer base would definitely end up migrating to the new networks. It would avoid a head-to-head competition between the LFCs and Telecom's vertically integrated network, which could see short-term price wars aimed at limiting market share loss by Telecom that would further distress the business plans for the LFCs.

It did, however, face one problem: timing. CFH was expected to be signing contracts with at least some intending LFC partners by 30 September 2010. The huge range of 
issues that needed to be resolved between Telecom, the Government, the Commerce Commission and CFH to allow its participation appeared to have no prospect of being resolved by that deadline. This raised the question of whether the deadline would be pushed out, or whether Telecom would simply find itself too late to participate - thereby tipping the situation back to the unpalatable options presented in preceding paragraphs.

In the event, however, the government made significant changes to the regulatory framework that would apply to the scheme in July 2010 (Joyce, 2010b). Instead of mandating that LFC investors could only operate the dark fibre-optic infrastructure, it required them to offer 'lit' wholesale services to all comers on an open basis. That is, LFCs would be required to provide wholesale services that, in the previous iteration of the scheme, they would have been banned from providing.

At the same time, and more remarkably given the earlier discussion about the role of the regulator, the government also decided that the LFCs should enjoy a statutory exemption from any price or non-price regulation by the Commerce Commission - a regulatory forbearance period or 'regulatory holiday'. CFH would have the job of regulating LFC activity for the first ten years, with the Commission's tools becoming available only after 2020. These policy decisions were reflected in the Telecommunications (TSO, Broadband and Other matters) Bill introduced to Parliament towards the end of 2010, and sparked the fiercest debates around the ongoing regulatory framework.

The regulatory forbearance period was the most controversial of the changes proposed in 2010. If the behaviour of market participants gave the Commission concerns that market power was being abused, which seemed to be the commercially logical outcome in other network industries with monopoly characteristics, then it was only after 2020 that the Commission could regulate price or non-price services offered by the LFCs.

This proposed approach flew in the face of one of the constant calls that regulated industries make: for regulatory certainty (Patterson, 2011). In the scheme, as proposed and outlined here, there was no certainty for investors. There was no offer 
of up-front regulatory coverage, which would give them a known set of regulated constraints within which to determine the economics of investing. There was no suggestion of a regulatory holiday at the point where the contractual obligations on price and open access come to an end--and such a regulatory holiday would be the opposite of what is widely considered to be best practice. This increased regulatory risk meant, all other things being equal, that less fibre would be built and fewer premises connected to fibre than would be the case in a more certain regulatory environment.

On the other side of this argument, however, was the fear by investors that the Commission would not take a reasonable time horizon into account. Large network investments are rarely profitable in the short term. If the losses in the short run were then followed by price regulation, once profits emerged in the long run, investment would be less likely to flow into the new networks. This concern was part of the motivation for the government suggesting the regulatory forbearance period.

In the end, political realities intruded on the government's plans. During the course of Parliamentary debate in 2011, it proved unable to secure a parliamentary majority for the proposal to implement regulatory forbearance. Government support parties withdrew their assent to these provisions following a determined lobbying campaign, some of which was quite public and vociferous. The concession was announced in May (Joyce, 2011).

While the other aspects of the changes were passed, the Commerce Commission's ability to regulate was left unimpeded. The eventual legislation repealed the accounting separation obligations implemented in 2006, and replaced them with a specific information disclosure regime aimed at establishing accurate cost information about the new fibre-optic networks for market monitoring and potential regulatory use. During the parliamentary process, the legislation was also amended to provide for the structural separation of Telecom, as outlined below.

The rationale for the government's attempt to remove regulatory oversight may also have been simply part of a larger agenda including the most significant change arising from the UFB initiative. When the final partner selections were made in May 
2011, Telecom was an agreed partner, with different financing arrangements in place than with the other smaller LFCs, and a footprint of close to $80 \%$ of the UFB rollout. To do this, Telecom was obliged to engage in structural separation. Chorus - the network unit created under the operational separation process - would become a stand-alone, separately-listed public company. It would secure some of the assets held by Telecom's wholesale division, with remaining assets in that division going to the rump Telecom business, which would retain ownership of the mobile network and the retail customer base. Chorus would become a regulated utility, controlling the fibre rollout in its agreed areas and the copper network nationally, and Telecom would become simply one among many retail service providers competing for custom.

The logic of structural separation has been canvassed above. Why did Telecom choose to engage in it? There were several benefits. It would be free of the intrusive operational separation obligations on the business. Instead of a complex three-way virtual split, a simpler two-box separation model would be imposed. The new network company would be able to be awarded the UFB, avoiding a situation where a new access network was being built to compete with Telecom's copper network. There was also the matter of the receipt of $\$ 900 \mathrm{~m}$ in public funds in a mix of debt and equity funding to roll out the new network. When finally passed, the legislation mentioned above included a relatively light touch oversight regime for the new separation arrangements, informed by public consultation in 2010 as to how to make legislative provision for this separation (New Zealand Government, 2010). It also rolled back some of the retail and wholesale regulation that had been in place on Telecom since the 2006 changes.

At the end of 2011, the new regulatory settlement was firmly in place. Chorus has commenced the UFB rollout as an integrated network firm with copper and fibreoptic assets. Its copper network remains regulated under substantially the same terms as it has faced since 2006, with the Commission continuing to regulate the terms of local loop unbundling and various bitstream services that access seekers use to deliver broadband across the cabinetised copper network. The new fibre-optic access network is being built in a manner that will see it able to be unbundled from 2020. Commerce Commission oversight of both copper and fibre-optic networks 
under the Telecommunications Act 2001 is firmly in place. The other LFCs will end up cooperating with Telecom and Crown Fibre Holdings to ensure that consistent wholesale products are available across the country to retail providers.

In both the copper and fibre-optic broadband worlds, there is now a vertical separation between the network owner and service providers. The ability and incentive for the network owner to discriminate against or in favour of a particular service provider is diminished already, and will further decline over time as Chorus' and Telecom's shareholder profiles change consistent with the different risks and rates-of-return the businesses will offer. The Commerce Commission retains the tools it needs to regulate the market should difficulties emerge. The only oddity remaining is the role of Crown Fibre Holdings, which managed the procurement of the networks and now has an uneasy role within the new market structure it has helped to create (TCF, 2012).

\section{Conclusions}

This chapter has examined the shift from general competition regulation of telecommunications in New Zealand to an industry-specific regulatory regime, and the on-going strengthening of that regime over the past decade. In the middle of the decade the focus shifted to providing stronger powers to the competition regulator and to restructuring the market in a manner that would help to support more competitive conditions for retail service providers, without the need per se for competition regulator involvement. This culminated in the complete vertical separation of networks from retail services in the historic copper and future fibreoptic world.

This is an unparalleled shift in approach, both in scope and in pace. There is no comparable jurisdiction where this degree of change has occurred within this time period. The only comparable case is Australia, where the construction of the National Broadband Network has occasioned the purchase by NBNCo of Telstra's copper network. But that is achieving the structural separation outcome by means of purchase rather than negotiation; and it ignores the fact that Australia maintained a 
telecommunications regulatory framework separate to general competition law from at least 1997, pre-dating the New Zealand legislation by four years (Given, 2010). Arguably this is consistent with Australia's generally more interventionist regulatory culture, but it does display the speed with which changes took place in New Zealand.

The drivers of change identified in the introductory chapter of this thesis can be seen playing out throughout the chapter. The critical nature of the infrastructure was held to be important by both Labour-led and National-led governments. In response, the New Zealand culture of liberal regulatory policy approaches drew to an end as the imperative of providing more competitive broadband markets drove a rising tide of regulatory intervention in the sector. The outcome at the time of submission is a regulatory framework that is comparable with usual practice in other OECD countries except for the vertical separation of both copper and fibre-optic networks, which is intended to ensure that the problems that vertical integration caused in the copper world are not repeated in future.

While both Labour and National fought various battles in the four periods of reform under consideration (Telecommunications Act 2001, unbundling decision in 2003, Telecommunications Amendment Act 2006 and Telecommunications (TSO, Broadband and Other Matter) Amendment Act 2011), the overall direction was not contested. The increasing level of intervention in telecommunications markets was agreed by both parties. The following chapter considers the other side of the rising tide of state intervention: the investment equation, with government making ever greater efforts to develop fast broadband for New Zealand, and spending increasing sums of money to achieve that outcome. 


\section{Case Chapter 2: Investment}

In any discussion regarding broadband policy, investment is important. The historic investment in telecommunications infrastructure in many places, including New Zealand, was managed by local and then national governments. The rollout of a nationally available and affordable telecommunications infrastructure, based on analogue copper technologies, was managed in New Zealand by a section of the Post Office, a government department (Moseby \& Purre, 2010).

Public funds were employed in rollout of the access network, and there was a legal monopoly for the state in providing this infrastructure, operating it to provide services to the public, and in regulating its use. As technology changed and as broadband became the new focus of telecommunications policy, rationales for investment by the public sector expanded. The traditional concern with service availability - the reach of the network - was joined by a new concern with the timeliness of availability of the new broadband technology.

Two scenarios - the 'never served' case and the 'too slow' case - justified investment decisions being considered. In the first, wide access to basic communications is a widely shared policy objective among advanced countries (OECD, 2008b). To ensure that the most remote areas had some Internet access was a consistent with earlier New Zealand efforts to ensure broad access to communications, and the scale of investment involved was small in absolute and relative terms, and not disruptive of existing investments made by the private sector but rather complementary to them.

In the second case, tackling the 'too slow' problem with public investment was a considerably more complicated decision. The creation of a new fibre-optic infrastructure is inevitably disruptive to the owners of the existing copper infrastructure. The scale of the investment is much larger. The mechanisms chosen to implement it are, therefore, more important, and receive a greater degree of scrutiny. Further, as discussed in the previous chapter, the state in New Zealand had 
adopted a wide array of changes to regulatory policy designed to develop competition and thus investment in broadband infrastructure, including the mandating of a large investment in improvements to the copper network through cabinetisation to allow higher speed broadband on Telecom's network. To be considering large, and potentially competing, investments at almost the same time (Telecom's commitment to upgrade the copper network was announced in late 2007 and agreed in March 2008, and National's commitment to invest in fibre through the Ultra-fast Broadband Initiative or UFB was announced in April 2008), brought very clearly to the fore the lack of confidence that the state (political leaders of both parties) had in market solutions to the 'too slow' problem (Moseby \& Purre, 2010).

The case described by the following sections indicates a rise in state involvement that is at the core of this thesis. Early efforts were focused on the relatively orthodox proposition of ensuring that the least commercially viable customers could obtain basic broadband services. By the end of the period, however, significant direct state investment in new fibre-optic infrastructure was under way. In the latter case with the UFB, a public-private model of investment was chosen, and the state's investment was being managed at arms-length by Crown Fibre Holdings (CFH). The new infrastructure would provide wholesale services only. The Australian model, of a single State company investing many billions to be a full service communications company, was not replicated; wholly state-owned networks were not developed, and nor was the earlier departmental model that served to roll out the previous generation of telecommunications infrastructure in New Zealand.

Politically, governments of the left and the right came to similar conclusions regarding the role for public investments. While incumbents made much of their imagination and foresight when deciding on the investments outlined in this chapter, opposition parties critiqued them as one might expect - but there was little heat in the criticism, because, as in the regulatory case, there was substantive agreement on the need for public action to solve the two problems of reach and timely rollout. The most expansive plans for investment in fact came from the National Party. The state’s involvement was designed to hasten a broader rollout of high-speed broadband than market investment decisions would have allowed. Disputes between the parties ended up focusing on whether the means chosen were most likely to 
achieve those objectives, which communities would receive service and which would miss out, and whether the administration of the investments was being done in the most effective way.

This chapter covers the five critical investment decisions made during the case period: Project PROBE, the Broadband Challenge, the Broadband Investment Fund, the Ultra-fast Broadband Initiative, and the Rural Broadband Initiative. It discusses these after canvassing the historical context of public investment interventions in telecommunications in New Zealand, and the investment impact (or lack thereof) of the KiwiShare.

Some investment areas are not covered in this chapter. In particular, there is no indepth discussion of the early history of universal service requirements for voice service by Telecom, as these largely predate and are not relevant to the broadband story. To the extent there are relevant matters, they are picked up in the following section on the KiwiShare and on Telecommunications Service Obligation.

In addition and perhaps less intuitively, the story of mobile broadband is not covered in any depth except in the discussion of the Rural Broadband Initiative towards the end of the chapter. The dynamics of investment in and regulation of mobile networks are outside the scope of this research, notwithstanding the growing importance of such network infrastructure for broadband Internet access. At the time of submission, most broadband is still used over fixed line connections (Commerce Commission, 2011), and the step-changes to wireless broadband connectivity which will become possible once the use of radio spectrum by analogue television broadcasting comes to an end in 2013 are still more prospective than immediate. In any case, a broader reach of high-speed fibre-optic networks makes future rollouts of wireless broadband more affordable, as mobile or wireless towers require connections to the core network, usually through fibre-optic networks. A fuller treatment of mobile issues would be recommended in any research which follows the story of state involvement in broadband markets in New Zealand in future years, as the profusion of mobile devices and consumer preferences for always-available broadband are likely to continue and intensify rather than the opposite. 


\section{The logic of public investment}

In any market economy, investment in infrastructure is often seen as a key determinant of future growth (Canning \& Pedroni, 2008). A wide array of networks, often provided by both private and public entities, supports the business, consumer and social activity of citizens. Be it in the provision of clean drinking water, affordable electricity, effective transport or many other areas, networks play an important role in modern life.

In keeping with New Zealand's liberal approach to economic policy outlined earlier, the state withdrew from investment in and operation of telecommunications during the 1980s. The Post Office was split into parts, with a new government corporation, Telecom, taking control of the telecommunications system. A large investment in digitisation of switching across Telecom's network followed as the new corporate model was bedded down. In one of the final acts of the Labour Government which instigated the reform programme, the corporation was sold to private purchasers for \$4.25bn in 1990 (Moseby \& Purre, 2010).

The New Zealand state, like other states, invested in telecommunications out of concern to ensure that the ability to communicate was available across New Zealand at an affordable price. The geography - both physical and urban - meant that, while large urban centres may well have been served by a private enterprise model of telecommunications investment, it would have been unprofitable to connect large parts of the rural sector and they would have been left without service. What regulation Telecom did face on privatisation was the KiwiShare obligation discussed at the beginning of the last chapter, and recapped briefly below (Howell, 2007).

By the end of the 1990s, however, technological changes had undermined the fit between the liberalised regulatory structure of telecommunications and growing social and economic demands for enhanced network capacities. The rise of widespread residential Internet connections, first dial up and later broadband, placed new demands on the network. These new demands required new investment to meet them, most particularly for the core network when dial-up Internet was prevalent, and for improvements both to the core network and the access network as demand 
for broadband began to appear in the late 1990s and early 2000s. As international examples of the rollout of fibre-optic broadband infrastructure began to appear, it became apparent that further investment would be required in order for New Zealanders to enjoy similar services to those enjoyed by residents of other advanced countries.

It was also clear that these investments would be an order of magnitude larger than those required to make piecemeal improvements to the existing copper infrastructure that had been made since the privatisation experiment began in 1990. By way of example, Telecom's capital expenditure in maintaining its network ranged between $\$ 400 \mathrm{~m}$ and $\$ 800 \mathrm{~m}$ per annum between 1990 and 2000. Investment in new facilities, as opposed to maintaining existing services, was only a small part of that sum. The capital required to roll out a ubiquitous fibre-optic network, however, was estimated at between \$4bn and \$8bn, depending on the reach of the network and the technology chosen to implement it (Network Strategies, 2008).

The objectives of state investment in communications were the same as in the past: universal access to the technology of the day. Efforts to resolve two particular market failures were evident in New Zealand's policies in this regard, as already mentioned. The first failure to be tackled was the simple availability of broadband facilities in remote and rural areas. Commercial imperatives led Telecom to invest most heavily in dense urban areas, where the market was largest and the return would be highest. This was the genesis of the first set of investment policies considered in this chapter - Project PROBE and the Broadband Challenge Fund.

The second failure was one of timeliness. As the first decade of the twenty-first century progressed, and as a range of jurisdictions began to roll out fibre-optic services to their residents, New Zealand faced a choice. It could maintain existing piecemeal investments at the edge of the copper network, and rely on market competition to drive future investment. Or, it could once again spend public funds on improving the speed of connectivity through the new technology on offer. The three subsequent initiatives discussed below - the Broadband Investment Fund, the UltraFast Broadband Initiative and the Rural Broadband Initiative, were all aimed at this 
larger scale, step-change investment in new infrastructure, though with important differences in terms of ambition.

In deciding to invest to solve this second problem, the government had to choose between distinctly different approaches. There was a broad choice between providing grants to public or private investors in network infrastructure; creating legislative monopolies or similar to drive investment; or directly investing public funds into entities that would provide such infrastructure, either on its own or in partnership with private sector investors. The legislative monopoly model was never seriously discussed in New Zealand, meaning that the main choice facing the state was between investing directly in infrastructure, and changing the investment incentives faced by other parties through providing grants to them.

In terms of the investment induced by each approach, grants would see more fibreoptic broadband infrastructure rolled out for a given sum of public money than would an equivalent direct investment (especially since the latter, by definition, demands a financial return) (Ministry of Economic Development, 2008), but would leave the state with little leverage in determining the use of the new infrastructure. This chapter details the debates between these different approaches, and the broad commonality of view that existed between the left and the right in implementing them.

\section{KiwiShare and the Telecommunications Service Obligation}

The earliest public intervention into investment decisions after privatisation of New Zealand telecommunications was 'KiwiShare', setting Telecom's obligations in terms of network coverage (Howell, 2008). Part of Telecom's company constitution, KiwiShare obliged Telecom to maintain the coverage of the network at least to the extent it had reached at the date of privatisation, and to make available to all residential customers a flat-rate line rental that included unmeasured local calling within defined local calling areas without additional charge. The cost of this line rental could only increase by the rate of consumer price inflation. This model obliged Telecom to provide coverage in the least profitable areas of the access 
network through cross-subsidies within Telecom from more profitable, urban parts of the access network.

With the changes to the regulatory framework brought about by the Telecommunications Act 2001, KiwiShare was converted to a Telecommunications Service Obligation (TSO), a legal instrument under the new Act (NZIER, 2003). While this device - the Local Service TSO, also called the KSO - maintained the network reach requirements and retail price control for local calling that were an earlier feature, it introduced limited compensation to Telecom to provide it. Instead of requiring solely internal cross-subsidies to meet the cost of "non-commercially viable" customers at the edge of the network, it passed that cost on to other telecommunications firms by means of an industry levy system, with the annual levy being determined by the Commerce Commission on an annual basis and shared among those firms using the network depending on their share of the relevant service market. Telecom, with $2 / 3$ of the sector's revenue, was required to meet around 2/3 of the assessed cost of such customers. The other providers had to meet the remaining third of the costs.

While this funding was notionally aimed at maintaining the reach and affordability of Telecom's network, the lack of published information regarding which groups of customers were viable and which were not kept the TSO in the headlines for the decade of its existence (Moseby \& Purre, 2010). Other communications providers consistently challenged the Commission's rulings on costs in the Courts, sometimes with success, and neither the Commission nor Telecom were ever able to conclusively demonstrate a credible link between the funds Telecom received under the TSO, and investment in the rural network which such funds were ostensibly expected to provide.

While the TSO was eventually replaced by new mechanisms under the Rural Broadband Initiative, it does stand along with its predecessor KiwiShare as the first state involvement in investment policy post-privatisation. While no direct public funds were employed, from 2001 funds requisitioned from all other communications providers under a state mandate were used, with the intention that the funds would improve communications infrastructure to part of the market. 


\section{Project PROBE}

Project PROBE (Provincial Broadband Extension) marked the first new stage of government spending on broadband infrastructure (Tooland \& Yoong, 2007; Moseby \& Purre, 2010). The project or projects known as PROBE were first announced as small scale pilots in 2001 by Paul Swain and Jim Anderton, respectively ministers of Communications and Regional Development (Swain, 2001). The full funding envelope as advised in the 2002 Budget was aimed at providing broadband Internet connectivity to 900 rural schools that would otherwise remain removed from advanced telecommunications services. It was also expected that the extension of connectivity would open up opportunities for economic development that would otherwise not be possible.

Funded by the Crown to a final sum of $\$ 45 \mathrm{~m}$, the project was led by a Steering Group composed of officials from Education, Economic Development, Prime Minister and Cabinet, Health, the State Services Commission, and a project management firm. Based on a Project Charter developed in August 2001, the Steering Group evaluated responses to a conventional RFI process, and eventually agreed to fourteen regions being covered by the programme. A fifteenth 'region' was intended to provide satellite broadband coverage to the most isolated schools.

The project was implemented through contracts let by the Project in eleven regions, while regional entities funded by PROBE funding, but managed independently, dealt with the remaining three. WOOSH Wireless was the chosen provider in the Southland region, while Telecom was the selected provider in most other regions. Auckland, Nelson/Tasman/Marlborough and the satellite region (a notional 'region' where coverage by physical infrastructure would be uneconomic, and so satellite connectivity was used instead) were independent providers. PROBE funding would be available up to the amount of the lowest compliant bid, but regions could choose to make additional investments alongside and choose a different bid if they wished.

Money provided by the programme was used for two main purposes (Tooland \& Yoong, 2007). It installed high speed links (generally copper or microwave radio) 
from rural areas back to the core network (known as 'backhaul'). One of the critical difficulties in providing broadband in those underserved areas was the lack of capacity back to the core network, and so this part of the project tackled that problem. The second purpose was to allow the provider to install cabinets in those areas with the DSLAM equipment required to provide broadband access to the targeted schools and to other potential customers in the areas near them. The satellite region was a service purchased from commercial satellite providers, and the wireless region from WOOSH involved its own wireless technology which required no physical links between its base transmission stations and the premises served.

Telecom's involvement was due to its ability to leverage existing network assets to provide improved services to schools. Some parties to the industry had hoped that the investment could see competing infrastructure put in place to change the competitive landscape, but this did not occur once Telecom had been selected as the provider in many regions. The government would have assumed at the time that the new regulatory framework in the Telecommunications Act 2001 would allow access to this new infrastructure to competing access seekers, if they wished to make use of it.

In terms of outcomes, PROBE was a success on its intended objectives of increasing access to broadband infrastructure by rural schools. It was completed mostly on time and at less than the final anticipated budget. By ensuring that such schools could connect to broadband services on similar terms to those in other parts of the country, an important principle of digital inclusion was observed. The infrastructure serving such schools, especially where a deal had been signed with Telecom for the region's coverage, inevitably improved broadband services to households and businesses near the additional backhaul and upgraded cabinet infrastructure involved.

This narrow, targeted intervention succeeded. It also set a precedent for state involvement in addressing the first scenario discussed - the 'never served' situation where the gap between the cost of servicing sparse rural populations and the revenue available from them was unlikely to lead to investments by the private sector. If the parallel regulatory reforms had had their desired effect in driving improvements in infrastructure in the urban areas, this pattern of state investment may have become 
the norm. The second step in such investment was in line with this approach, with the rollout of the Broadband Challenge Fund.

\section{Broadband Challenge Fund}

In 2005 the Labour-led government established the next stage of public investment policy in New Zealand as part of its first Digital Strategy (New Zealand Government, 2004a). The Strategy identified the need for public assistance in rolling out broadband in underserved areas. It was also intended to provide seed funding for the establishment "of up to fifteen Urban Fibre Networks" according to the then Minister, Hon David Cunliffe (Cunliffe, 2006a) (Cunliffe, 2006). In announcing successful grant recipients in November 2006, the Minister stated the purpose of the intervention was to speed the availability and adoption of high-speed broadband:

The Broadband Challenge seeks to provide ready access to very high speed networking in our urban centres, and better and more affordable access in rural and underserved areas. (Cunliffe, 2006c)

The fund was given $\$ 24 \mathrm{~m}$ to use as seed funding over four years. Recipients were expected to be viable community-based providers bringing at least matching funding to the agreement, and that clearly had the management, technical and financial resources to make their investments happen. Two programmes were developed: one for urban areas, where speeds were expected to be around 1 gigabit per second, and aimed at priority users; and one for remote and underserved areas, where no speed requirements were established. Funding was allocated through a competitive bid process.

The regulatory reforms of 2001 were not felt to have delivered (InternetNZ, 2006a), and so, in parallel with the changes to the Telecommunications Act that were implemented in 2006, targeted investment was applied in order to speed up the rollout of high speed broadband. The lack of such services was seen as a barrier to economic growth and development in New Zealand. The method chosen to tackle them was a contestable fund, aimed at securing the maximum possible matching 
investment from other prospective investors, to roll out a mix of fibre-optic and wireless infrastructure.

So the themes of limited, targeted investment in a relatively liberal framework are reflected in this second, small-scale investment intervention by the Labour-led government. This scale reflects the interconnected nature of the policy package of which it was part. Together with other complementary measures set out in the Digital Strategy, and the regulatory package discussed in the previous chapter, this policy package amounted to the most significant intervention in broadband markets since Telecom was privatised in 1990.

\section{Broadband Investment Fund}

Labour's Broadband Challenge Fund, characterised above as the most significant intervention since privatisation, is today clearly a precursor to the more ambitious investment programmes that followed. The multi-billion dollar public-led investments announced by the National Party in 2008 and implemented by the start of 2012 are an order of magnitude larger, but follow in the path of direct government investment in broadband infrastructure that Labour set out.

While the regulatory reforms in 2006 led to a framework to address the competition issues affecting the copper network, global attention was turning to the need for the replacement of the copper network, aged and designed for delivering voice services, with new fibre-optic infrastructure that would be the next major innovation in the communications infrastructure of advanced countries. As part of the ongoing evolution of policy towards a more interventionist stance and a greater willingness to invest public funds, this change in focus was already evident with the Broadband Challenge Fund outlined above, with its focus on radically higher broadband speeds including fibre-optic access networks in metropolitan areas.

To understand the rationale for investment in new networks, a brief explanation of the characteristics of fibre compared with copper is required. As noted previously, fibre-optic cabling from the premises to the core network is incomparable with 
copper cabling: optical networking faces no practical speed constraints caused by loop length. Data can be transmitted along an intact optical path at the speed of light, and does not slow or disperse over the short distances involved in a telecommunications access network. Further, an optical path can contain more than one light wavelength at a time, and the amount of data each wavelength can carry (as well as the number of wavelengths transmitted and received) is limited only by the electronic devices at each end of the optical path. As such, fibre-optic networks offer theoretically limitless data capacities, which is not the case with copper metallic paths which rely on electro-magnetic transmission of data. Optical fibre is also more durable once installed, cheaper to maintain, and cheaper in the first instance than copper.

Numerous jurisdictions were by 2008 rolling out fibre-optic infrastructure, and it was only a matter of time before the policy debate in New Zealand began to focus on the upgrade of the main telecommunications infrastructure to fibre (Given, 2010; Milner, 2009). The regulatory framework was able to level the playing field and drive competition in a world of well-established copper networks, known services and ways of operating. It was not obviously well-suited to inducing the investments required to roll out a completely new physical plant across the country at an estimated cost of $\$ 4 \mathrm{bn}$ to $\$ 6 \mathrm{bn}$ to reach three-quarters of households and business premises (Network Strategies, 2008). This was a result of both the scale of the investment, and the risks inherent in rolling out a new network to compete with an existing sunk-cost copper network. The owner of that copper network faced few opportunity costs in competing with a new fibre-optic network, while the fibre network owner would have significant investments to pay back, and few guarantees of customers without radical changes to demand.

The Labour-led government refreshed its Digital Strategy (New Zealand Government, 2008), trumpeted Telecom's cabinetisation programme, and introduced, as the centrepiece of its 2008 election year plans, a new Broadband Investment Fund or 'BIF', designed to make up to $\$ 340 \mathrm{~m}$ in grant funding available to further the rollout of higher speed, copper-based broadband services (Given, 2010). In contrast, the National opposition announced in April 2008 a policy to see a new fibre-optic access network connect up to $75 \%$ of New Zealand households, and 
a direct public investment of up to $\$ 1.5 \mathrm{bn}$ of public funds in order to bring this about (Key, 2008).

The National Party plan, the Ultra-Fast Broadband Initiative, is discussed in the next section. Of interest is that it was only the previous year that the National Party leader had said his party was not considering direct investment in fibre-optic infrastructure, preferring in principle a grant system similar to Labour's earlier efforts - and to the Labour plan discussed in this section (O'Neill, 2007). Between July 2007 and April 2008, the New Zealand Institute published an influential report "Defining a broadband aspiration" setting out its view that high speed broadband infrastructure would benefit the New Zealand economy by between $\$ 2.7 \mathrm{bn}$ and \$4.4bn per year, and that without such investment, the economy would not prosper (New Zealand Institute, 2007). This report was released in September 2007 and sparked widespread debate. Labour and National's more comprehensive 2008 policy approaches took that debate into account, both being expansions compared with earlier policy (on Labour's part) or stated intentions (on National’s part).

Before considering the detail of the Broadband Investment Fund, which was Labour's most advanced plan for telecommunications policy to date (the Party’s 2011 communications policy did not commit it to a radically different approach to that adopted by the National government outlined below), a brief reflection is in order. In its approach to broadband issues, as shown by the modest investment programmes discussed above and the regulatory reforms canvassed in the previous chapter, the Labour Party retained a degree of faith in market outcomes (Given, 2010). The focus through the middle part of its time in power was on the regulatory changes discussed in the previous chapter. The efforts set out in the Digital Strategy in 2004 were consistent with this market approach: they focused on coordinating and developing demand, and improving the skills of citizens in their prospective use of the technology.

This approach was consistent with what most other jurisdictions were doing at the time, and was consistent with the liberal policy paradigm in New Zealand, focused as it was on leaving markets generally free, and seeking to replicate and extend the reach of competition through regulatory adjustments where bottleneck facilities 
meant competition was not viable. But there were hints in the investment policy decisions Labour was making that it did not believe that competitive market solutions would provide the whole answer. The Broadband Investment Fund was the largest step into the investment area, demonstrating that point with complete clarity (Milner, 2009). Had Labour retained faith that the regulatory framework would deliver its desired outcomes, it would never have developed the BIF.

A centrepiece of Digital Strategy 2.0, and indeed of the 2008 Budget, was the announcement of a Broadband Investment Fund. As mentioned above, this marked the height of the party's proposed public investment in the sector, and was an order of magnitude larger than the Broadband Challenge funding of 2005: the package was intended to spend $\$ 340 \mathrm{~m}$, compared with around $\$ 25 \mathrm{~m}$ in the earlier experiment in public funding.

The Fund offered three main programmes: $\$ 250 \mathrm{~m}$ in urban grants, $\$ 75 \mathrm{~m}$ in grants to underserved rural areas, and a $\$ 15 \mathrm{~m}$ investment in anchor tenancy of a new transTasman cable (New Zealand Government, 2008). Urban deployment was designed to provide open access to dark fibre or ducting infrastructure to all comers, and applications were not restricted to telecommunications businesses - local authorities and others were entitled to apply too. In rural areas the focus was on extending broadband access in areas where none (defined as service over 1mbps) was available, with less stringent open-access requirements reflecting the greater challenge in rolling such infrastructure out in rural areas. Both funds were to be made available through competitive rounds of tendering, with maximum private investment per dollar spent in grants to be a key criterion in the selection of grant recipients.

Officials argued explicitly that a grants-based approach would be "the most effective means of leveraging substantial private sector investment in key aspects of broadband infrastructure” (Ministry of Economic Development, 2008). The Fund was announced in Budget 2008 (22 May), with applications closing in September 2008 and the first round of funding decisions announced in November 2008, only weeks before the general election. A media release by David Cunliffe advised that applications were oversubscribed (both the rural and urban funds were limited to 
making grants of a maximum of 30\% of their total amounts in any one year), indicating a considerable degree of interest by a range of parties - including some that already had fibre in the ground, and who were looking to leverage that investment with some assistance (Cunliffe, 2008).

Abruptly, that is the end of the BIF story. There are no ongoing impacts to consider and no record in the rollout of the plan to discuss, because the incoming National government cancelled the programme shortly after taking office. None of the grants were ever paid and none of the infrastructure the initial selections had committed to was ever rolled out. It was only three years later at the end of 2011 that the results of public investment policy began to become real with fibre-optics beginning to roll out as part of the UFB.

In summary, Labour's approach at the end of its time in government retained a degree of faith in the ability of market-led initiatives to deliver the broadband infrastructure that New Zealand needed, but had buttressed this with increasingly ambitious investment programmes designed to accelerate the rollout of fibre-optic broadband infrastructure. National's argument for a different model, based on direct investment rather than grants, was intended to deliver fibre-optic infrastructure more widely - but it too aimed at investing to speed up the rollout process. Economic imperatives remained at the forefront of the Labour government's thinking, and while the quantum of investment proposed was larger than the previous Broadband Challenge Fund, the mechanisms involved in the Broadband Investment Fund were very similar.

The increasing trend towards public investment will have given some in Labour some unease. It is perhaps an illustration of a sort of policy path dependency. While there was an increasing degree of state intervention exhibited already on the regulatory side of the debate, and so far in this chapter with respect to investment, there are policy bounds outside which a particular government led by a given set of people will not step. For the New Zealand Labour Party, always concerned with proving its economic credentials to markets and commentators who tend to be more critical of its approach and thus to give it less space for manoeuvre, the notion of a 'nation-building' programme of expansive state investment in broadband was 
perhaps more difficult to conceive of at the beginning of its time in office. By the time the Broadband Investment Fund was launched, however, this discomfort had passed. The liberal approach had faded and the interventionism had spread from the regulatory side to the investment side of the broadband policy debate (Milner, 2009). The door to an active state investing in important infrastructure New Zealand needed was now wide open.

This begs the question of why Labour did not respond to National's UFB proposals with a similar proposal for direct investment. The pressure to match National's offer, with a clear target of three-quarters of the public having access to fibre-optic broadband within ten years, must have been strong. There is a possibility the explanation lies in a simple reason: exhaustion. By the time of the 2008 Budget, David Cunliffe had held the Communications portfolio for over three years. While he demonstrated an ongoing flow of new ideas (for instance, Digital Strategy 2.0), the senior key drivers of the Labour Government, in a policy sense, had all been members of the Cabinet since 2002. Many had held office since 1999. The demands placed on Ministers in terms of time, public attention and scrutiny are considerable in-and-of themselves. The demands grow when a small and tight team are driving a policy agenda conceived of in the middle of the 1990s and implemented from 1999 onwards. A degree of intellectual exhaustion was apparent in Labour by the time of the 2008 election, which may have contributed, at least to some degree, to the Party's unwillingness or inability to make a step-change in its policy approach to broadband in response to National's gambit.

However, an alternative explanation is also credible and perhaps simplest: Labour was convinced that its programme of grants was superior to National's proposed direct investment programme, delivering more investment per dollar of public funds (Ministry of Economic Development, 2008). It would also see fewer disruptions to the very significant investment plans of private sector operators, not least Telecom with its \$1.4bn programme of cabinetisation which commenced in 2008 (Cunliffe, 2008). Notwithstanding the arguments advanced by the New Zealand Institute discussed in the following section (New Zealand Institute, 2007), the government did not change its view on this. An evolving, competitive marketplace, with targeted assistance via grants to bridge the investment gap and allow the rollout of high speed 
broadband infrastructure, was a relatively orthodox approach to the transition, and did not require investment decisions of the scale or complexity required by National's plan - to which this chapter now turns.

\section{Ultra-fast Broadband Initiative}

National's election victory in 2008 marked a change of approach to the technicalities of broadband investment policy, but not to the overall trend of a increasing level of investment by the government. The methods used, as already indicated, were a break with those of Labour's decade in office. National moved toward a more interventionist, public-sector-led investment approach. It assumed that the development of a widely available high-speed broadband network would create its own demand (Key, 2008). Finally, it left questions of 'where next?' with the regulatory framework up in the air for a considerable period of time - in fact until four months before the 2011 General Election.

The policy is perhaps emblematic of the New Zealand state's retreat from a highwater mark of liberal policymaking in the 1980s and 1990s. Instead of providing grants to private firms, National was intent on direct government investment in network infrastructure. This was a break with the past in terms of method, if not in terms of objective. The intriguing point to bear in mind through this chapter is that it was the more market-friendly National Party that chose to make that break, rather than the less market-friendly Labour Party. This shift away from market liberalism is not unique to New Zealand policymakers (OECD, 2008b), but the scale of the change in New Zealand was considerable. As in the regulatory sphere, there was broad agreement between the two parties that higher speeds were needed, and so the overall consensus already identified held in this example of investment intervention.

The genesis of the policy is simple. In April 2008, National Party leader John Key made a speech to the Wellington Chamber of Commerce (Key, 2008). In it, he announced that his party had decided to commit itself to a significant direct investment of public funds in the rollout of an Ultra-Fast Broadband Initiative: a state-coordinated and -led public-private partnership designed to make fibre-optic 
communications networks available to $75 \%$ of New Zealand households over a period of ten years.

In introducing the plan, Mr Key dwelt on the role of infrastructure in the economy, argued that the Labour government had made insufficient investments in it, and pledged to resolve this as a priority if his party was successful in the general election later that year. Key also argued that investing more in conventional infrastructure would not deliver a step change to the way the economy was operating, and stated his view that ultra-fast broadband would be required to allow that to occur. He said:

The future prosperity of our economy depends on it. So, in the coming months you can be sure of hearing more from me about repairing New Zealand's infrastructure deficit. (Key, 2008)

The essence of the plan was simple (New Zealand Government, 2009). A new national fibre-optic broadband network would be rolled out in a public-private partnership, delivering fibre to the premises of those in the coverage area (around three-quarters of the population). Up to $\$ 1$.35bn of public funds would be on the table to induce the needed \$3-\$5bn of private funds needed to build the network.

As with all telecommunications investments and market structures, the complexity in the detail was a critical issue for government to address as it worked out the implementation of the proposal, and much of this section considers that detail. The detail is complicated, and is best described in three phases: the initial plan worked out by Government, the modifications made in 2010, and the changes made during the Parliamentary end-game in 2011. Even the establishment of the details of the initial plan took almost a year. The details of the process for signing contracts to start rolling the fibre out were agreed in November 2009 (New Zealand Government, 2009), and the commercial bidding process began at that point. Policymakers hoped contracts would be signed with providers towards the end of the third quarter in 2010, although, in the end, this process took far longer than anticipated, in part because of the two major changes mentioned above and detailed below. 
A new company, Crown Fibre Holdings (CFH) was established to be the government shareholder in the new investment, and to negotiate the agreements with private sector partners. New companies (Local Fibre Companies or LFCs), each being a public-private partnership between CFH and private investors, would be established to build the new networks. They would focus on the deployment of fibre-optic cabling along streets and to the premises in the selected coverage areas. Their role would be to roll out the infrastructure and to sell access to it, on an open access basis, to service providers. The latter would 'light the fibre,' or provide the electronics to send data along the fibre, and deliver the range of services households and businesses were looking for.

Importantly, the LFCs would not be permitted to deliver services direct to the public themselves. The insight driving this was the same as that which led the debates around operational and structural separation of Telecom canvassed in the previous chapter. Vertical integration of the telecommunications industry, with network, wholesale and retail service providers all in one organisation, would give the network provider the incentive and ability to discriminate against third party wholesale or retail service providers in favour of its own operations. The new infrastructure, part financed by public investment, would be structured in a way that gained the benefits of this separation from the beginning. As a key part of this programme, participation in the scheme and control of any particular LFC was restricted to those parties who did not have majority control over any wholesale or retail network. This presented an obvious problem for Telecom, as well as for any of the other major telecommunications providers, and ended up being one of the drivers of changes to the scheme discussed below (Given, 2010).

The commercial model developed by the government for the rollout of the infrastructure, as set out in the initial proposal, was a novel component of the plan (Moseby \& Purre, 2010). To focus public investment on the least commercially viable parts of the rollout, it was decided that the public funds provided to each LFC would be the amount required to build 'Communal Infrastructure' - the fibre-optic cables in each street, and the cabinets to service the network, as well as any local links back to fibre 'central offices' within the LFC's area (the fibre world equivalent of telephone exchanges, where all the lines from a given coverage area terminate and 
are connected to the national network, the Internet and other services). The commercial partners would provide funding for the per-premises connection costs within the LFC area (from the street cable to the wall), and, as it did so, it would repay to $\mathrm{CFH}$ the share of the communal infrastructure cost represented by that connection (New Zealand Government, 2009). By way of example, if the total communal infrastructure costs divided by the number of premises to be served came to $\$ 1,500$ per premises connected, then, with each connection, the LFC partner would invest the cost of the connection from the street cable to the premises plus repayment of the $\$ 1,500$ to $\mathrm{CFH}$.

By adopting this commercial model, the government was undertaking the riskiest part of the investment itself, effectively removing risk from the private partner. If nobody could be persuaded to connect to the new network, the private partner would face no investment cost and the government funds would remain sunk. As rollout proceeded, they would only be paying for the cost of the Communal Infrastructure that was notionally in use to allow that connection. For the government, the benefit of this approach was that it would lead to capital being returned to $\mathrm{CFH}$ as people were connected, allowing that capital to then be freed up for re-investment in new areas where LFCs had not yet been signed or where funds had not yet been available to be deployed. While at any one time the maximum public capital invested would be $\$ 1,350 \mathrm{~m}$, it could effectively buy more investment than that over time due to this recycling effect.

When bids were being assessed over 2009/10, the picture emerged that the government's model did not add up: the capital available through the scheme would not allow for the infrastructure to be built at affordable wholesale cost, given the cost of capital that the private investors faced. The combination of risk, total cost and cashflow prospects from the business model of the LFCs only being able to offer access to the fibre-optic infrastructure would not allow them to compete effectively against the regulated price of the existing copper network. Something had to give. In July 2010, the government announced changes to the model designed, in the Minister's words, to “further improve the business model for local fibre companies and facilitate additional co-investment from the private sector” (Joyce, 2010b). 
The substantive changes made were: to expand the layers of the network operated by the LFCs; to reduce the open access requirements on the LFCs and defer them (at layer 1) until 2020; and, to implement a regulatory forbearance period where the Commerce Commission's ability to regulate price- and non-price terms of access to the new networks would be restricted, also until 2020. Each of the three changes was significant, and together they generated a great deal of political conflict over the scheme which, until that point, had not been subject to a great deal of opposition from the Opposition.

The regulatory aspects, particularly the impact of the regulatory forbearance period, are covered in the previous chapter. The change to allowing LFCs to offer services at both layer 1 (direct access to the fibre) and layer 2 (the provision of a lit bitstream circuit on that fibre over which retailers could provide service) was driven by a competition concern among retail providers. They felt that the risk of a monopolist market participant securing lighting rights for the dark fibre, and then extracting rents from retail providers due to their sole ability to offer access to customers on the network, was real - due at least in part to the considerable resources required to light the fibre, and the relatively small scale of most of the competing access seekers.

This fear was accentuated by the network design option likely to be used in deployment of mass-market fibre-optic broadband infrastructure, known as gigabit passive optical networking or 'GPON'. The GPON issue bears brief examination. There are two broad ways to install a residential fibre-optic network (Network Strategies, 2008; Alcatel-Lucent, 2009). One method sees direct fibre strands being run to each premises along a street, so there is a separate fibre strand all the way from the central office to the premises. This is much as the original copper network operated, as described in the previous chapter, before the implementation of fibre-fed cabinets. It is referred to usually as Point to Point fibre or 'P2P'. The alternative approach is to install a single strand of fibre down the street, with sixteen or thirtytwo premises having short connecting fibres joining them to it, and 'passive' optical prisms sharing the light path between them. GPON is one implementation of this approach. 
P2P architecture is marginally more costly, but provides a single optical path to the premises with no sharing of light or services. GPON architecture requires technology at the end of the street feeder cable to give retail service providers only access to their customer, not to all the customers on the cable - but costs less. In a P2P architecture, unbundling of service provision is a simple task: the fibre strand which runs from the premises to the central office can easily be connected directly retailer's equipment located there. With GPON architecture, and with the technologies current at the time of writing, the infrastructure owner that controlled the electronics that disambiguated the light paths in the street feeder cable was the gatekeeper of the services to all the premises connected.

This technology and network architecture issue helps to explain the preference of retail operators for LFCs to offer services at layer 2. By ensuring the LFCs had to provide lit services, this problem would be avoided, as the LFCs behaviour could be regulated by Crown Fibre Holdings through its contracts with them at their establishment, and because the open access requirements imposed on them would require them to treat all retail providers equally. There would be no new, unregulated monopoly unintentionally created. There was a further advantage to this - providing lit services meant that the overall revenue of the LFC would be higher, allowing them access to a larger pool of capital and better able to service the debt and equity they would have to incur in building the network.

The second major change to the UFB framework announced in July 2010 was a change to the open access requirements (Joyce, 2010b). 'Open access' is a concept which sees an infrastructure owner obliged to treat all parties equally when they are using its facilities. Where the owner provides services using its own infrastructure, it is obliged to consume the same base services via the same processes and on all the same terms as any other party. The intention is to reduce the infrastructure provider's ability and incentive to discriminate in its own favour for commercial reasons. The stronger form of this is 'equivalence of inputs', where all terms, processes, systems and so on must be exactly the same. The weaker form is 'equivalence of outcomes', where different processes might be used, but where the outcomes are intended or expected to be the same. In tandem with the offering of services at layer 2 , the government removed the obligation to provide any layer 1 
services until 2020. So instead of a choice being available to service operators as to whether they would use layer 1 services, in the mass market, only layer 2 would be available, unless the LFC chose to make such services available on its own initiative. The effect was a potentially less competitive and dynamic sector, with infrastructure owners being the only party likely to light fibre until 2020.

The third change was the most significant and far-reaching. The model set out in 2009 had been clear that there was no justification for exempting the new networks from the regulatory oversight of the Commerce Commission under the Telecommunications Act. Yet in July 2010, the Minister proposed a regulatory holiday for the new networks, saying:

The Government is changing the ITP model to avoid burdening infant businesses investing in emerging technologies with inappropriate regulation. Prices will be set by CFH through negotiations following the tender process, and there will be limited scope for regulatory intervention to alter those prices while the industry is still immature. However, there will be safeguards in place to ensure that effective competition will develop. (Joyce, 2010b)

The previous chapter, on regulatory interventions, has discussed the problems with this approach, creating as it did a conflict of interest for the Government. As noted there, the final legislation did not include this, after the government proved unable to secure the support in Parliament to legislate for it, and the LFCs are now under the oversight of the Commission under the Telecommunications Act 2001, with all the usual regulatory powers being available should they be required.

The final point to note was that Telecom had maintained an interest and involvement with the scheme through its development, notwithstanding the fact that as a vertically integrated operator it was not eligible to be awarded a UFB contract. Its involvement in any form was possible because the initial Invitation to Participate in 2009 allowed providers to make a proposal that was "not compliant” with the rules of the scheme, so long as they also made a compliant proposal (New Zealand Government, 2009), which Telecom may well have done pro forma. 
Telecom's first sign of acceptance that it likely could not be involved while remaining vertically integrated came in May 2010, when as mentioned previously the CEO stated that structural separation was under consideration (McBeth, 2010). The mechanics of this process were considerable: if signed as a partner, Telecom would have to separate the ownership of its network business from its retail business. This would be a substantial change compared with the virtual nature of the operational separation settlement that began in 2008. Telecom had offered a form of structural separation during the 2006 select committee process, but the government had not taken that offer up and little had been heard about it since.

Through more than a year's debate and negotiation, the government and Telecom shaped an approach to structural separation. While this was happening, Crown Fibre Holdings continued to negotiate a deal for the UFB project with Telecom and other parties. The government's consideration of structural separation included public consultation in September 2010 (New Zealand Government, 2010) as to the form it might take and how it would be managed within the Telecommunications Act framework - or what changes to that framework might be required.

In the end, the discussions were successful, and Telecom was signed as a UFB partner in early 2011, with the full legal separation of the company into network and retail arms occurring in November 2011. The separation was not only applied to the new fibre-optic networks, but also to the existing copper network. In the spectrum of interventions on the regulatory side in the market-shaping debate, this was the greatest possible separation - secured as part of the negotiation to make the investment programme work.

Telecom's participation was never guaranteed. This permitted CFH to sign early deals with lines companies and draw out pressure on Telecom, particularly with regard to the regulatory settlement it would face in a situation of structural separation. Telecom secured the ability to invest in fibre-optic broadband infrastructure and to manage migration from its existing copper network on its own terms, facing no competition from fibre investors. It also secured the end of its onerous operational separation settlement mentioned above, with the complex operational separation model being replaced by a simpler 'two-box' separation 
between the network and the service business. This saved Telecom considerable expense. For its part, the Crown secured a new market structure where the problems of vertical integration would be left in the past, and a build partner for around $70 \%$ of the UFB footprint, though without the above-described capital recycling model being put in place for Telecom. Instead, a mix of equity and debt-financing was agreed with Telecom, to the value of around $\$ 900 \mathrm{~m}$. This secured the total UFB build for around $\$ 1200 \mathrm{~m}$, when the contribution to the other LFCs (structured as the scheme initially expected) was included.

Through a complicated evolution, the scheme landed largely as described with the changes from June 2010. At the time of submission, LFCs including Chorus (Telecom's new network company, legally separate from Telecom) are constructing fibre-optic networks and retail services are expected to be available before the end of 2012. Consideration of the implications of this model follows in the conclusion to this chapter. Before that, however, the question of the remaining $25 \%$ of the population, not covered by the UFB scheme, is discussed. The Rural Broadband Initiative was the matching investment scheme for those parts of the country outside the UFB footprint.

\section{Rural Broadband Initiative}

National's UFB initiative was only designed to end up with coverage of around three-quarters of the New Zealand population. The government only arrived at the need to provide a related scheme in rural areas slowly, and only under pressure from powerful rural interest groups, including the Federated Farmers organisation (Moseby \& Purre, 2010). It was in the course of a television interview in 2009 that Prime Minister John Key committed the government to a significant investment package to improve telecommunications access in rural areas (Pullar-Strecker, 2009).

The pressure for this was in part based on a sense of grievance by rural dwellers, and in part by economic need. At a Rural Broadband symposium in Rotorua in November 2009 at which the author was present, Conor English, the Chief Executive 
of Federated Farmers, argued that the entire premise of the UFB was backwards. In his view, public investment should instead be rolled out from the rural periphery to the urban core, given the possibility that competition in those areas with the greatest population density (particularly under the new regulatory arrangements introduced in 2006) would deliver private investment to meet urban needs, which could never occur in rural areas.

Conor English’s brother is Bill English, the Deputy Prime Minister, Minister of Finance and deputy leader of the National Party. National's support base as shown by the results at successive general elections is strongest in provincial and rural New Zealand, aside from some wealthy inner-city electorates (New Zealand Electoral Commission, 2008). The absence of an investment plan for rural areas was clearly not politically tenable, and John Key's concession of an investment plan on television sparked hurried policy development in the Ministry of Economic Development. The final package developed was the Rural Broadband Initiative or RBI, which was initiated in late 2009 (Joyce, 2009), developed in 2010 and began to be implemented in 2011.

The key feature of the scheme was that it provided fibre-optic backhaul to all settlements with 500 or fewer people, with such fibre to be available to all potential access seekers on an open-access basis (Ministry of Economic Development, 2011). In an echo of the earlier Project PROBE, the main targets were rural schools, with most getting direct fibre access (the least accessible 3\% of rural schools would remain dependent on microwave radio or satellite links). The scheme was established by a competitive tender process, and a key criterion in the selection of bidders was to be the anticipated spill-over benefits to local communities. In other words, it sought to leverage the fibre-optic backhaul provided to the school to bring faster residential and business broadband offerings in these small communities.

Funding for the scheme was established at $\$ 300 \mathrm{~m}$, to be paid as a grant (not a direct investment) to the successful bidders. The government agreed to contribute $\$ 48 \mathrm{~m}$ from taxes - the same sum as initially established for investment in rural broadband. To finance the remaining $\$ 252 \mathrm{~m}$, the government restructured the Telecommunications Service Obligations that were outlined at the beginning of this 
chapter. Instead of having the Commerce Commission calculate the cost to Telecom of providing local calling service in non-economic areas, the TSO levy was replaced with a new Telecommunications Development Levy, to be struck at $\$ 42 \mathrm{~m} /$ year for six years to fund the RBI. The TSO obligations on Telecom (and now Chorus) were not, however, repealed: the government argued that, over the entire customer base covered by the copper network, net revenue for Telecom was positive. Accordingly, the TSO obligation could be met through internal cross-subsidies within Telecom itself for as long as it applied (Ministry of Economic Development, 2010).

The tendering process saw a range of bids made, but the final contracts were signed to a joint bid between Telecom/Chorus and Vodafone, New Zealand's largest mobile carrier. The fibre that would provide access to schools would connect Chorus cabinets where practicable. Vodafone committed to building around 150 new openaccess mobile towers, which would be available for other access seekers to use in providing wireless broadband services. It would also provide a bitstream-type product on its existing infrastructure (on broadly open-access terms) in the rest of the RBI coverage area where it already had backhaul and towers in place (Ministry of Economic Development, 2011).

National's decision to award the project to a collaboration between the two largest players gave many in the industry pause for thought, especially when combined with the government's attempt to reduce regulatory oversight in the UFB initiative (Jackson, 2011). It remains to be seen whether the tender structure and the product specifications, combined with the open access obligations imposed as part of the tender, will be adequate to address these competition problems. While Chorus is now no longer a provider of retail services, separated as it is from (retail) Telecom in its new role as the UFB fibre provider, Vodafone remains vertically integrated, and will not be required to meet equivalence of inputs standards in its provision of service to third-party access seekers. This leaves a concern that, as the vertically integrated Telecom used to do, Vodafone will have the ability and incentive to discriminate against other prospective providers of wireless service to rural dwellers.

RBI will roll out fibre to most rural schools, and to provide the opportunity for faster broadband services in rural areas - both fixed line and wireless broadband. It is a 
considerable upgrade to rural infrastructure which will end up seeing new investments in the order of around $\$ 500 \mathrm{~m}$ when completed. For the expenditure of $\$ 48 \mathrm{~m}$ of taxpayer funds, this is a considerable amount of investment delivered to a core constituency of the National Party in the period running up to a general election. The economic use made of the services allowed by this infrastructure will be of interest to scholars in coming years.

\section{Conclusions}

This chapter has canvassed the rise of state investment in broadband networks in New Zealand in the past decade. A range of investment programmes have been implemented, of increasing scale and both by means of direct investment, and by means of grants to private parties, to roll out improved broadband infrastructure in both rural and urban New Zealand. This increasing trend of state investment was intended to ensure that most New Zealanders had access to high-speed broadband services sooner than reliance on private sector investment intentions would have allowed.

Increasing the role of the state in this fashion was a policy pursued by both Labour and National (Milner, 2009). The small beginnings of Project PROBE evolved over ten years to the significant investments in the RBI and UFB projects that will be a lasting legacy of the National government elected in 2008. In 2012, the National Party's broadband policy appears to represent at least in part the beginning of a new approach that is less than recognisably consistent with its recent historic approach to economic management. Traditions of economic interventionism that the party appeared largely to have turned away from after the experience of the Muldoon government in the 1970s and 1980s (Gustafson, 1986) are back on the table. Whether this points to a broader shift in National's approach will be discussed below.

The liberal push (inaugurated by Labour in the 1980s) resulted in the end of the state's role in owning and operating telecommunications infrastructure. Labour assumed that contract and competition law would create an environment where the 
private sector would be able to give New Zealanders access to the services they needed at reasonable prices. That basic framework is disrupted by a more interventionist approach, once again initiated by Labour, which reverses each of those key components of the earlier reforms: the return of state investment, and the introduction of a sector-specific regulatory regime being chief among them.

What is also of interest is the constituencies being appealed to. Labour's investment programmes were initially focused on the 'edges' of the market, taking careful steps to reduce the inequities of market-provided broadband infrastructure. In doing so, the Party was not making a calculated pitch to appeal to its own demographic or geographic constituencies: it was clearly operating in National Party territory, and only with the final attempt to invest in urban areas in meaningful ways with the Broadband Investment Fund of 2008 did its investing policies focus on delivering this infrastructure to its own core constituencies.

Likewise, but in a reversed sense, National's flagship UFB initiative was focused mainly on urban areas of New Zealand, with rural interests being largely ignored until that constituency reasserted its political power within the government to secure a better settlement. Notwithstanding that, the bulk of policy energy, political effort and taxpayer funds were invested in the thirty-three urban areas comprising threequarters of New Zealand's population - among them, all the sources of political support for National's primary political opponents in the Labour Party.

Each party's approach presented the other with obvious political opportunities, but these were not taken. The similarities between the two parties' approaches are, in the realm of investment as in the realm of regulation, more important than the differences. The political disputes outlined throughout this chapter are ones about method and approach. They are not substantive fights about the importance of making high speed broadband available; about the need for a fibre-optic network infrastructure to do this; or about the presumed economic benefits of making such services available

The imperatives both parties have been responding to in government are largely the same. The ability to access high quality communications infrastructure is indeed seen 
as a critical factor in future growth prospects of the New Zealand economy, and both regulatory changes and investment decisions have been justified by this importance. The palpable national sense of 'falling behind' other jurisdictions in the timely availability of such infrastructure joins the growing sense of importance it is seen to have for New Zealand's prospects to explain both the growing tide of state investment, and the growing impact of regulatory control on the market.

That is the primary lesson this chapter and the previous one show. Despite the rhetorical commitment of many governments, officials and politicians regarding the so-called importance of free markets, it is clear that political decisions have a very significant influence over the telecommunications industry. Its structure has been changed, from vertically integrated to vertically separated; and its technology has been upended, from copper to fibre - all by means of decisions not of telecommunications companies or private investors, but by those of the New Zealand government. 


\section{Conclusion}

The case study presented in this thesis explores the trajectory of increasing state involvement in the telecommunications industry in New Zealand in the period since 2000. Over the course of four Parliaments with governments of a variety of political complexions, the trend has been an increase in regulatory and investing interventions that have taken New Zealand from an outlier on the deregulatory side of the equation, to an outlier on the interventionist side (Given, 2010). New Zealand and Australia are the only two countries with widespread state-led rollout plans in place for fibre-optic broadband infrastructure. This represents a clear change from the liberal orthodoxy that the private sector should lead telecommunications investment, and that the role of the state is limited to enforcing generic competition law. The similarities between the approaches of National and Labour are of considerable interest, and the reader's attention is drawn to this as a key factor worthy both of consideration now and in the future.

Telecommunications is not the first time that New Zealand's major parties have converged around policy preferences. The liberal approach established by Labour in the 1980s, a departure from its ideological traditions, was followed up and extended by National in the 1990s. This created the policy paradigm in place at the beginning point of the case study in 2000 (Hazledine, 1998). Regardless of the fact that the Labour tradition would usually be seen as more accommodating to intervention in markets, the case study shows the inverse to have been the case: Labour in some ways retained more confidence in market mechanisms than National did, and its approach in the investment realm in particular showed that faith through to the end of its time in office in a formal sense, if not necessarily a substantive one. After all, while the mechanisms of the Broadband Investment Fund were clearly marketfriendly, the fact of a $\$ 340 \mathrm{~m}$ grant pool to drive the rollout of infrastructure clearly showed the limits of the Labour government's confidence in market mechanisms alone driving the scale of investment required. 
The similarity is clear. Both parties pursued regulatory strategies designed to separate the network infrastructure from service delivery - Labour in respect of the copper network, National in respect of the new fibre-optic networks. Both parties pursued a policy of increasing levels of state investment in order to induce private investments that would accelerate the availability of infrastructure compared with what would have been achieved otherwise. The logic for these interventions is apparent at least in part from the opening quotes in the introduction of the thesis, from David Cunliffe, Helen Clark and John Key: the infrastructure was seen as a vital component of New Zealand's future economic success. Relatedly, the pervasive fear of New Zealand policymakers of somehow being 'left behind' by other jurisdictions was also at play, as evidenced by the frequent and alarmed references to broadband rollout and takeup in New Zealand as compared with the rest of the OECD countries (New Zealand Institute, 2007).

In making these interventions, there was little debate about the fundamental question on the table: whether they were justified by the gains that fibre-optic communications networks were expected to give. Neither those expectations, nor the concept that the investment would be beneficial, were seriously tested. Conflict between Labour and National focused instead on the means being used (grants or direct investment, type of regulatory intervention), or on the degree or extent of intervention being warranted in achieving the goal. They were second order considerations but they were the only ones where public clashes arose during the case.

Taken together, these initial two arguments - a fear of falling behind, and a conviction that a particular infrastructure was important for the economy's future do not at first blush appear to be particularly persuasive account. Why would the state engage in multi-billion dollar investments or in far-reaching regulatory change that transformed an industry with billions of dollars in private capital already invested simply on that basis? Conventional explanations for policy change (for instance Richardson, 2000; Holzinger \& Knill, 2005) do not support a case for many of the changes documented in this case, except with one important exception, that of the Rural Broadband Initiative investment programme. 
Firstly and as already mentioned, the ideological frameworks of the two political parties that led governments during the period of the case would generally seem to indicate different approaches to the role of the state. National, as a conventional centre-right party in a liberal polity, is generally more in favour of market-led solutions to policy problems. The party accepted some of Labour's early reregulation in the sector, accepting that the market power of Telecom justified some interventions, but would not have been expected on the face of things to embark on a major nation-building project on its return to office. The counterpoint to this argument is that as well as a tendency towards more liberal economic approaches, National's history includes examples of significant state intervention in economic development and infrastructure, particularly the programmes that came to be known as Think Big - large state investments in energy and industrial infrastructure in the 1970s and early 1980s. So a tradition of the party is consistent with the approach taken post 2008, but it is an older tradition than the more contemporary market liberalism with which the party has generally been identified (Gustafson, 1986). It is more likely that National would have preferred not to be intervening in markets to the extent it was, but felt obliged to do so nonetheless.

For Labour the increasing role of the state has been less problematic in ideological terms. As a fairly conventional social democratic party that adopted elements of Tony Blair's “third way” approach to politics in the 1990s and 2000s, a respect for market liberalism was combined with a belief in the capacity of the state through targeted interventions to improve on market outcomes. That combined approach is obvious through all of Labour's policy initiatives 1999-2008: increasing regulatory focus first on granting access to the bottleneck facilities in Telecom's copper network, and then a new focus on the market's structure through operational separation. Through its period in office Labour moved toward a slowly increasing degree of investment which focused in the early years on extending copper based broadband services to un-served rural areas through Project PROBE, through to the focus at the end of its term in office on investing in new fibre-optic infrastructure in urban areas. Those urban areas were, at the beginning of the case, well-served by the private investment decisions of telecommunications providers by the standards of the time. 
If ideology does not represent a powerful explanation of the similarities in approach between the two parties, neither does constituency building or satisfying the desires of either parties' core voter support, with one important exception. In the 2000s, Labour's strongest support was from urban areas where voters are relatively deprived on a socio-economic basis. National's strongest support was from rural and provincial areas, and from the wealthiest urban suburbs (New Zealand Electoral Commission, 2008). These two geographic bases of support are enduring and clearcut features of the New Zealand political landscape since the realignments of the 1920s and 1930s, and would intuitively see National being more supportive of broadband improvements in rural areas, and Labour in urban ones, with a subsidiary focus by Labour on the affordability of such services that National would not necessarily match.

Counter-intuitively, the actual focus of the policies involved was in some ways the reverse of this. The regulatory policy that Labour adopted in its reforms were mainly aimed at facilitating urban investment, which led to higher quality of service and lower prices in the core urban areas as competing telcos made use of Telecom's copper network once local loop unbundling occurred. Yet those investments were targeted in suburbs which were higher income suburbs or inner city areas in the first instance, generally speaking. National's regulatory initiatives were largely following in the logical direction Labour had established. Dealing with the structural separation of Telecom was the only major additional change, and the impact of this in terms of a rural/urban divide is minimal.

Investing policies, on the other hand, represented to some extent an inversion of what one would have expected given the bases of support outlined above. Labour's first investment was in the most remote schools; its second investment policy through the Broadband Challenge was in small scale initiatives many of which were in small towns or provincial/rural areas. It was only towards the end of its period in office that large investments were proposed for urban areas where Labour's core support is found. Likewise for National, in a broad sense: the UFB initiative was focused mainly on urban areas, with initially only $\$ 48 \mathrm{~m}$ allocated for rural broadband improvement. It was in this rural area that the clearest example of a party rewarding its own supporters came about. The investment chapter of the case study 
outlined the emergence of the Rural Broadband Initiative, and the escalation of investment in that area from $\$ 48 \mathrm{~m}$ to $\$ 300 \mathrm{~m}$ following pressure from well-organised rural advocacy groups. Besides Federated Farmers, there was also pressure from a range of other groups including Rural Women. It appears clear from the sequence of policy change that National was reacting to a sense of grievance among strong supporters in adopting a more ambitious rural investment programme.

To some extent this exception to the inversion argument does show the significant inversion in the main policy approaches to investment. Labour focused on rural areas, and National on urban ones. With that said, it is important to note again the recurring theme in the case: that there was little political dissent from either side of the political divide. National did not especially protest Labour's regulatory plans or investment initiatives, and Labour did not criticise the direction of National's policy. Both parties criticised the other's implementation of policy, and these criticisms were discussed in the preceding case chapters, but at the level of direction and intent, the similarities remain at the core of the story.

Focusing more closely on those organised interests connected with political parties, and setting aside the linkages between rural lobbies and National's Rural Broadband Initiative, interest groups did not play a major role. The typical interest group influences on political parties arise from the ability to mobilise either support among voters, or finance for electoral purposes. The coalition of interests pursuing telecommunications reform in most respects was quite limited and quite narrow. User interests like the Telecommunications Users Association of NZ (TUANZ) and Internet New Zealand worked with friendly media to argue for change, but neither organisation commanded a great deal of public profile or support, and the media stories generally stayed off the front pages and were confined to technical press in a way that limited their mainstream visibility or salience.

The traditional organised supporters of the Labour party in the trade union movement were broadly supportive of the direction of regulatory initiatives the Labour-led governments implemented (Council of Trade Unions, 2010), but did not have a great deal to say on the investment side of the ledger. Traditional organised supporters of National were cautious about the regulatory changes (some calling, for 
example, the regulatory imposition of operational separation of Telecom 'theft' and demanding compensation for shareholders who lost capital value in their shares due to regulatory changes (New Zealand Business Roundtable, 2006)). They were however broadly supportive of the investment plans, which would see more affordable high speed broadband investment faster than the market would otherwise deliver it. The state was broadly seen as enhancing the rollout of much needed infrastructure rather than, for instance, competing with private firms in its delivery.

There is no doubt that the selection of Telecom's Chorus wing for the rollout of the UFB, and the selection of incumbents Chorus/Telecom and Vodafone for the rural broadband initiative, will have assuaged some of the concerns that the business community may have had with a more state-led approach to rolling out this infrastructure - for instance, through LFCs organised to compete with incumbent service providers. It finally is worth noting that the strong opposition of those groups representing incumbent providers to much of the investment - for example a critical report commissioned by Telecom, Vodafone and TelstraClear in opposition to investment plans in 2008 (Castilia, 2008) - made little impact on governments of either political stripe.

In respect of two other vectors of policy change, foreign intervention and elite opinion formation, the story is similar. There is little evidence that foreign intervention was behind the changes to regulatory policy. New Zealand's trade partners have often sought changes to policy in this country - a recent example being pressure by the United States on New Zealand to change its copyright law regime (Bell, 2011), and an earlier example being pressure by the same country to change New Zealand's nuclear free legislation. Such foreign pressure does not always yield results, but is almost always capable of influencing the tone of policy debates in New Zealand and the options which are seen as credible or possible.

In respect of the second channel for changing views, elite opinion formation, there are limited examples to draw on. The Castilia study mentioned above, which opposed intervention plans, was discounted by government. The New Zealand Institute paper arguing for ambitious public intervention in broadband markets and providing a simple estimate of the gains it believed could accrue from such an 
investment, did have an impact on National's policy formation (New Zealand Institute, 2007). OECD commentaries (OECD, 2008b) had influence in the general shape of interventions and more particularly on the regulatory policy debates (the organisation was a strong proponent of unbundling of the incumbent's copper local loop infrastructure as a means of generating more competition in communications markets). InternetNZ published a study by Network Strategies setting out cost estimates for the installation of ubiquitous broadband infrastructure, but the study did not analyse the proposed benefits (Network Strategies, 2008). So none of the studies or efforts to influence the opinion of policymakers contained the typical judging of costs against benefits which are often at the core of policy change.

The broader point raised by Peter Katzenstein (Katzenstein, 1985) is a different aspect of elite opinion which seems relevant. New Zealand, as a small, peripheral state in the global economy, faces constrained policy choices in many dimensions. Its elites typically focus their efforts on improving the country's position on the international stage, rather than in disputing each other's objectives. This technocratic approach to significant policy questions shows through in other areas of policy, but is readily apparent in the case here.

Related to this possible source of pressure for change is the opinion of government policymakers. It is outside the scope of this research to obtain direct comments from ministers or public officials who were involved in these debates. While officials broadly supported the re-regulatory changes in 2001 and argued in favour of unbundling in 2003/04 when the regulator made a decision opposed to it, they were not necessarily convinced by the larger scale investment programmes that emerged later in the decade. This was particularly case with the UFB's direct investments by the state in infrastructure companies. Those programmes were policy entrepreneurship by politicians, not by the established civil service, and the challenge the civil service faced was broadly to do with resolving the contradictions inherent in some of the politically sketched details of the plans, rather than either encouraging politicians into investment plans they had not already decided to do - or in persuading politicians to go back on plans they had publicly committed to implementing. If the latter circumstance had occurred, only the protagonists involved 
would currently be able to comment on the nature of those conversations, but there is no public evidence to support an argument that this occurred.

A final and related point to note is that in many jurisdictions, changes in regulatory and policy frameworks are induced by those responsible for regulating the particular industry. In New Zealand, the Telecommunications Commissioner established by the Telecommunications Act 2011 might have been expected to lead debates about changes to regulatory policy. This did not however prove to be the case. The most important regulatory decisions - the structure of the market, the regulation of new services - were taken by the governments of the day and implemented through legislation. All of the investment policies were of course initiated by governments. There were no regulatory initiatives at all led by the Commissioner, with the one chance they had for significant change - the discussion regarding unbundling in 2003/04 - being unwillingly accepted by government, and then overturned by legislation only two years later. The extent to which this lack of agency on the regulator's part relates to its own structural constraints as a semi-independent regulator requiring political signoff for major decisions, and narrow powers under its founding legislation, is a matter worthy of future consideration that is outside the scope of this research.

While none of the explanations above provide a comprehensive explanation to the case of similarity, together they do give some pointers. A broad ideological commitment to liberal non-interventionism faded on both sides of the political spectrum in the face of experience with less-interventionist models and their failure to deliver the desired outcome. Pressure from interest groups was in favour of reform but not an overwhelming source of energy for change. Constituencies of the two major parties only made one decisive intervention and that was in favour of investment in rural areas.

The discussion then returns to the drivers of the comprehensive changes wrought on telecommunications infrastructure in New Zealand, which can be summed up in three propositions: the perceived importance of this infrastructure for New Zealand's economic success, the relative slowness of private investment in delivering the infrastructure, and pervasive fear of 'falling behind' other jurisdictions if the 
infrastructure was not built in a similar time period to that of other countries. This logic bears out the increasing levels of state involvement in markets formerly dominated by private decision making, both on the regulatory and investment sides of the equation. Changes overseas were constantly raising the bar, meaning ambitions of a few years before were out of date before they were met. The discourse of falling behind was pervasive in parts of the national discourse in this period, and lent itself to the communications landscape with little amendment.

New Zealand governments could have responded to this pressure in a number of ways. They could have chosen to rely on competitive markets and confined themselves to regulatory interventions designed to facilitate the private sector's rollout of infrastructure. They could have built the infrastructure themselves. In the event, they chose neither of these approaches but instead to regulate and to invest piecemeal to cover gaps in the infrastructure, and then as the global momentum towards rolling out fibre accelerated, adopted broader and larger investment plans to make such infrastructure available to most of the community. They did so in a manner that was reasonably respectful of existing arrangements on the investment side, working with incumbent providers to transition to new infrastructure rather than inducing infrastructure based competition with existing providers. They also actualised those investment decisions through traditionally market friendly means grants and or public/private partnerships, rather than direct state construction of the infrastructure concerned.

In so doing they exhibited a policy paradigm clearly within New Zealand political traditions, but operating to a perceived imperative which never itself received detailed scrutiny. For while it was true that other countries were rolling out this infrastructure, the empirical or theoretical cost/benefit was never established by either political tradition in government. Costs and benefits were tangentially in mind, but nation-building appeared in the end to be the driving force. New Zealand could not and would not be left behind - but what precisely would be being missed out on was never made particularly clear. Perhaps the logic was similar in the end to that employed by the New Zealand state two centuries earlier, when it was investing at great expense in electricity distribution networks: some benefits of the technology were known, but the full impact was not. The private sector was not building it; other 
countries were. New Zealand needed to keep up, and would be missing out if it did not.

Given that the impacts of the Internet are as yet imperfectly understood and that the possibilities of economic gain from the Internet have only just been touched on so far, twenty years into its mass adoption, these investments may yet prove to be a farsighted preparation for the country's future without which New Zealand really would have been left behind. Whether that is the case will unfold in coming years as fibre-optic access is rolled out, which is now happening: the result of ten years of very significant change in New Zealand telecommunications policy.

FINIS 


\section{Reference List}

AAS. (2008). Cabinetisation and local loop unbundling: the way forward. InternetNZ. Retrieved February 25, 2012, from http://internetnz.net.nz/system/files/workstreams/Cabinetisation_LLU_Repo rt.pdf

Alcatel-Lucent. (2009). National Broadband Network: strategies for fibre distribution. Retrieved February 27, 2012, from http://www.alcatellucent.com/wps/PA_1_A_9C1/DocumentDownloadFormServlet?LMSG_CA BINET=Docs_and_Resource_Ctr\&LMSG_CONTENT_FILE=White_Papers /GPONvP2P.pdf\&lu_lang_code=en_WW

Alcatel-Lucent. (2012). Building the Benefits of Broadband. Auckland: AlcatelLucent. Retrieved February 23, 2012, from Alcatel-Lucent: http://www.alcatellucent.com/wps/DocumentStreamerServlet?LMSG_CABINET=Corporate\& LMSG_CONTENT_FILE=Country_Content/Australia/WP_Building_Benefi ts_Broadband_2012.pdf

Baldwin, R., Cave, M., \& Lodge, M. (2012). Understanding regulation: theory, strategy and practice. Oxford: Oxford University Press.

Bell, S. (2011, July 4). NZ needs to protect itself from US corruption: Harvard professor. Computerworld. Retrieved February 16, 2012, from http://computerworld.co.nz/news.nsf/news/nz-needs-to-protect-itself-fromus-corruption-harvard-professor

Benkler, Y. (2006). The wealth of networks: how social production transforms markets and freedom. New Haven: Yale University Press.

Blankart, C., Knieps, G., \& Zenhäusern, P. (2008). Regulation of new markets in telecommunications: market dynamics and shrinking monopolistic bottlenecks. European Business Organisation Law Review(8), 413-428. Retrieved December 17, 2011, from Regulation of New Markets in Telecommunications: Market Dynamics and Shrinking Monopolistic Bottlenecks

Boles de Boer, D., \& Evans, L. (1996). The economic efficiency of telecommunications in a deregulated market: the case of New Zealand. Economic Record, 72(216), 24-35. doi:10.1111/j.1475-4932.1996.tb02606.x

Bortolotti, B., D'Souza, J., Fantini, M., \& Megginson, W. L. (2002). Privatization and the sources of performance improvement in the global 
telecommunications industry. Telecommunications Policy, 243-268.

Retrieved January 16, 2012, from

http://bernardobortolotti.com/Userfiles/attach/20107281619144Privatization \%20and\%20the\%20sources\%20of\%20performance.pdf

BusinessNZ. (2011). A more competitive New Zealand: BusinessNZ's manifesto for the 2011 general election. Wellington: BusinessNZ. Retrieved January 26, 2012, from

http://www.businessnz.org.nz/file/2189/A\%20MORE\%20COMPETITIVE\% 20NEW\%20ZEALAND\%20BusinessNZ's\%20Election\%20Manifesto\%2020 11.pdf

Canning, D., \& Pedroni, P. (2008). Infrastructure, long-run economic growth and causality tests for cointegrated panels. The Manchester School, 76(5), 504527. doi:10.1111/j.1467-9957.2008.01073.x

Castilia. (2008). Getting the most from high speed broadband in New Zealand: investing in productivity growth. Retrieved December 16, 2011, from http://www.castaliaadvisors.com/files/Castalia_Getting_the_Most_from_High_Speed_Broadban d_Final_Report.pdf

Cave, M. (2006). Encouraging infrastructure competition via the ladder of investment. Telecommunications Policy, 223-237. doi:10.1016/j.telpol.2005.09.001

Cave, M., \& Doyle, C. (2007). Network separation and investment incentives in telecommunications. University of Warwick Business School. Retrieved February 12, 2012, from http://www.kigeit.org.pl/FTP/ap/sot/07_11_12_podzial_2.pdf

Cave, M., Majumdar, S., \& Vogelsang, I. (2002). Handbook of telecommunications economics: volume 1. Oxford: Emerald Group Publishing.

Clark, H. (2006, February 14). Prime Minister's Statement to Parliament. Wellington. Retrieved February 17, 2012, from http://beehive.govt.nz/speech/prime-minister\%E2\%80\%99s-statementparliament-0

Commerce Commission. (2003). Telecommunications Act 2001: Section 64 review and Schedule 3 investitation into unbundling the local loop network and the fixed public data network. Final Report. Commerce Commission. Retrieved January 12, 2012, from http://www.comcom.govt.nz/assets/Telecommunications/Archive/s64review-and-investigation-into-unbundling-the-local-loop/Investigation-intounbundling-the-local-loop-final-report.pdf 
Commerce Commission. (2007). Standard Terms Determination for the designated service Telecom's unbundled copper local loop network. Decision 609. Wellington. Retrieved January 27, 2012, from http://www.comcom.govt.nz/assets/Telecommunications/STD/UCLL/Final/F inal-UCLL-Standard-Terms-Determination-Decision-609.pdf

Commerce Commission. (2010). Summary and analysis of Telecom Corporation of New Zealand Ltd's regulatory financial statements for the year ended 30 June 2009. Commerce Commission. Retrieved February 16, 2012, from http://www.comcom.govt.nz/assets/Telecommunications/TelecomSeparation/Accounting/Summary-and-Analysis-of-Telecom-RegulatoryFinancial-Statements-for-the-Year-Ended-30-June-2009.pdf

Commerce Commission. (2011). Annual Telecommunications monitoring report. Commerce Commission. Retrieved July 12, 2011, from http:/www.comcom.govt.nz/assets/Telecommunications/MarketMonitoring/2010-Annual-Telecommunications-Monitoring-Report-29-April2011.pdf

Council of Trade Unions. (2010). Alternative Economic Strategy: an economy that works for everyone. Wellington: Council of Trade Unions. Retrieved February 27, 2012, from http://union.org.nz/sites/union.org.nz/files/NZCTU\%20Alternative\%20Econ omic\%20Strategy_1.pdf

Crandall, R., Eisenach, J., \& Litan, R. (2010). Vertical separation of telecommunications networks: evidence from five countries. Federal Communications Law Journal, 62(3), 493-539. Retrieved January 25, 2012, from http://www.law.indiana.edu/fclj/pubs/v62/no3/7\%20CRANDALL_FINAL.pdf

Cunliffe, D. (2006a, February 8). Keen interest in Broadband Challenge Fund. New Zealand Government. Retrieved January 12, 2012, from http://www.beehive.govt.nz/node/24845

Cunliffe, D. (2006b, May 3). Government moves fast to improve Broadband. New Zealand Government. Retrieved January 12, 2012, from http://www.beehive.govt.nz/release/government-moves-fast-improvebroadband

Cunliffe, D. (2006c, November 27). Broadband Challenge rolls out with Smartlinx3. New Zealand Government. Retrieved January 12, 2012, from http://www.beehive.govt.nz/node/27861

Cunliffe, D. (2008, November 6). Broadband Investment Fund oversubscribed. Wellington. Retrieved January 16, 2012, from 
http://www.beehive.govt.nz/release/broadband-investment-fundoversubscribed

Easton, B. (1997). In stormy seas: the post-war New Zealand economy. Dunedin: Otago University Press.

Fukuyama, F. (1992). The end of history and the last man. London: Penguin.

Given, J. (2010). Take your partners: public private interplay in Australian and New Zealand plans for next generation broadband. Telecommunications Policy, 34(9), 540-549. doi:10.1016/j.telpol.2010.07.012

Gustafson, B. (1986). The first 50 years: a history of the New Zealand National Party. Aucklanf: Reed Methuen.

Hammond, R. (2012, February). Personal correspondence.

Hausman, J., \& Sidak, J. G. (2005). Did mandatory unbundling achieve its purpose? Empirical evidence from five countries. Journal of Competition Law and Economics, 1(1), 173-245. doi:10.1093/joclec/nhi005

Hausman, J., \& Sidak, J. G. (2007). Telecommunications regulation: current approaches with the end in sight. Retrieved July 12, 2011, from National Bureau of Economic Research: http://www.nber.org/chapters/c12568.pdf

Hazledine, T. (1998). Taking New Zealand seriously: the economics of decency. Auckland: HarperCollins.

Holzinger, K., \& Knill, C. (2005). Causes and conditions of cross-national policy convergence. Journal of European Public Policy, 12(5), 775-796. doi:10.1080/13501760500161357

Howell, B. (2007). A pendulous progression: New Zealand's telecommunications regulation 1987-2007. Wellington: New Zealand Institute for the Study of Competition and Regulation (Inc). Retrieved April 2, 2011, from http://www.iscr.co.nz/f378,10548/10548_Pendulous_Progress_v_4_12_Nov. pdf

Howell, B. (2008). Strategic interaction under asymmetric regulation: the 'Kiwi Share' in New Zealand telecommunications. Wellington: New Zealand Institute for the Study of Competition and Regulation (Inc). Retrieved October 23, 2010, from http://www.iscr.co.nz/f467,13555/13555_ITS_Strategic_Interaction_Under_ Asymmetric_Tariff_Regulation.pdf

Howell, B., Meade, R., \& O'Connor, S. (2009). Structural separation versus vertical integration: lessons for telecommunications from electricity reforms. Wellington: New Zealand Institute for the Study of Competition and 
Regulation (Inc). Retrieved January 24, 2012, from

http://www.iscr.co.nz/f505,14787/14787_Separation_vs_VI_in_Electricity_a nd_Telecomms_April09.pdf

International Telecommunications Union. (2010). World Telecommunications/ICT Development Report. Retrieved January 24, 2012, from International Telecommunications Union: http://www.itu.int/dms_pub/itu-d/opb/ind/DIND-WTDR-2010-PDF-E.pdf

InternetNZ. (2006a, February 1). Submission to the Minister of Communications and IT on regulatory reforms . Wellington. Retrieved February 12, 2012, from http://internetnz.net.nz/our-work/submissions/submission-ministercommunications-and-it-regulatory-reforms

InternetNZ. (2006b, August). Submission to the Finance and Expenditure Committee on the Telecommunications Amendment Bill. Wellington: InternetNZ. Retrieved January 14, 2012, from http://internetnz.net.nz/system/files/submissions/Submission\%20to\%20the\% 20Finance\%20and\%20Expenditure\%20Committee\%20on\%20the\%20Teleco mmunications\%20Amendment\%20Bill\%20.pdf

InternetNZ. (2008). InternetNZ Briefing to Incoming Ministers. Wellington: InternetNZ. Retrieved July 12, 2011, from InternetNZ: http://internetnz.net.nz/system/files/submissions/INZ\%20BIM.pdf

InternetNZ. (2011, May 24). InternetNZ says time to now look forward. Wellington. Retrieved January 26, 2012, from http://www.scoop.co.nz/stories/SC1105/S00060/internetnz-says-time-tonow-look-forward.htm

ISPANZ. (2006). Submission on the Telecommunications Amendment Bill by Internet Service Providers Association of New Zealand (ISPANZ). ISPANZ. Retrieved July 23, 2011, from http://ispanz.org.nz/pdf/letters/ISPANZ_Submission_on_TB.pdf?PHPSESSI $\mathrm{D}=\mathrm{ff} 91 \mathrm{eff} 4 \mathrm{~d} 5 \mathrm{e} 16 \mathrm{~d} 5 \mathrm{e} 4 \mathrm{e} 1 \mathrm{ca} 54 \mathrm{e} 882 \mathrm{cc} 07 \mathrm{f}$

Jackson, R. (2011, February 10). Devil's in the detail when comparing RBI bids. Computerworld. Wellington. Retrieved February 12, 2012, from http://computerworld.co.nz/news.nsf/news/devils-in-the-detail-whencomparing-rbi-bids

Joyce, S. (2009, September 10). Govt announces targets for rural broadband. Retrieved February 22, 2012, from http://www.beehive.govt.nz/release/govtannounces-targets-rural-broadband 
Joyce, S. (2010a, March 16). Rural telecommunications plans finalised - media release. Retrieved February 23, 2012, from http://www.national.org.nz/Article.aspx?articleId=32304

Joyce, S. (2010b, July 1). UFB Model Amendments Announced. Retrieved January 23, 2012, from http://www.crownfibre.govt.nz/news/governmentupdates/ufb-model-amendments-announced.aspx

Joyce, S. (2011, May 18). Regulatory forbearance to be replaced. Retrieved February 7, 2012, from http://www.crownfibre.govt.nz/news/governmentupdates/regulatory-forbearance-to-be-replaced.aspx

Katzenstein, P. (1985). Small states in world markets: industrial policy in Europe. Ithaca, N.Y.: Cornell University Press.

Kedgley, S. (2001, December 18). Telecommunications Bill, third reading. New Zealand Parliamentary Debates.

Kelsey, J. (1997). The New Zealand Experiment: a world model for structural adjustment? Auckland: Bridget Williams Books/Auckland University Press.

Key, J. (2008, April 22). 2008: Achieving a Step Change - Better Broadband for New Zealand. Wellington. Retrieved February 17, 2012, from http://www.national.org.nz/Article.aspx?ArticleID=12143

King, S., \& Pitchford, R. (1998). Privatisation in Australia: understanding the incentives in public and private firms. The Australian Economic Review, 31(4), 313-328. doi:10.1111/1467-8462.000076

McBeth, P. (2010, May 24). Telecom mulls structural separation, looks to shift some burden back to govt. Retrieved January 26, 2012, from BusinessWire: http://www.scoop.co.nz/stories/BU1005/S00713.htm

Milner, M. (2009). Playing the telecommunciations game in New Zealand: The evolving story of telecommunications public policy in New Zealand. Telecommunications Journal of Australia, 59(2), 26.1-26.17. doi:10.2104/tja09026

Ministry of Economic Development. (2008, May). Broadband Investment Fund: draft criteria and proposed process for consultation. Wellington. Retrieved August 23, 2011, from http://img.scoop.co.nz/media/pdfs/0805/Broadband_Investment_Fund.pdf

Ministry of Economic Development. (2010, November 23). Regulatory Impact Statement: reform of the telecommunications service obligation framework and industry levy arrangements. Retrieved January 19, 2012, from http://www.treasury.govt.nz/publications/informationreleases/ris/pdfs/rismed-tsof-nov10.pdf 
Ministry of Economic Development. (2011). Rural Broadband Initiative: Questions for telecommunications industry. Retrieved February 25, 2012, from http://www.med.govt.nz/sectors-industries/technology-communication/pdfdocs-library/broadband-policy/RBI-Q-and-A-for-Industry.pdf

Monti, G. (2007). EC competition law. Cambridge: Cambridge University Press.

Moseby, S., \& Purre, J. (2010). Toward universal broadband access in New Zealand. International Telecommunications Union. Retrieved April 17, 2011, from http://www.itu.int/ITU-D/asp/CMS/Docs/NZ_broadband_case.pdf

Neill, A. (2001, December 18). Telecommunications Bill, third reading. New Zealand Parliamentary Debates.

Network Strategies. (2008). Broadband Strategy Options for New Zealand: analysis of possible infrastructure models. Network Strategies Report Number 28040. Retrieved July 17, 2011, from http://internetnz.net.nz/sites/default/files/workstreams/Broadband_Strategy_ Options_for_NZ_-_Stage_2_Report.pdf

New Zealand Business Roundtable. (2006). Submission on the Telecommunications Amendment Bill. Wellington. Retrieved March 21, 2011, from http://www.nzbr.org.nz/site/nzbr/files/submissions/submissions2006/060915telecommunications.pdf

New Zealand Electoral Commission. (2008). E9 - Results of the 2008 General Election. Retrieved October 12, 2010, from http://electionresults.govt.nz/electionresults_2008/e9/html/statistics.html

New Zealand Government. (2000a). New Zealand Telecommunications Inquiry: Terms of Reference. Wellington. Retrieved February 12, 2012, from http://www.scoop.co.nz/stories/PA0002/S00313.htm

New Zealand Government. (2000b). New Zealand Ministerial Inquiry into Telecommunications: Final Report.

New Zealand Government. (2004a). Digital Strategy. Ministry of Economic Development.

New Zealand Government. (2004b). Implementation Review of the Telecommunications Act. Ministry of Economic Development.

New Zealand Government. (2006, May 3). Cabinet Policy Committee: Minute of Decision. POL Min (06) 7/9. Wellington: New Zealand Government. Retrieved February 16, 2012, from http://www.beehive.govt.nz/Documents/Files/Cabinet\%20paper\%20and\%20 minute.pdf 
New Zealand Government. (2008, August). Digital Strategy 2.0. Ministry of Economic Development.

New Zealand Government. (2009, October). Ultra-Fast Broadband Initiative: invitation to participate in partner selection process. Ministry of Economic Development. Retrieved February 6, 2012, from http://www.crownfibre.govt.nz/media/4824/invitation-to-participate.pdf

New Zealand Government. (2010, September). Discussion document: Regulatory implications of structural separation. Wellington: Ministry of Economic Development. Retrieved February 12, 2012, from http://www.med.govt.nz/sectors-industries/technology-communication/pdfdocs-library/communications/telecom-separation/regulatory-implications-ofstructural-separation-september-2010.pdf

New Zealand Institute. (2007, September). Defining a broadband aspiration: how much does broadband matter and what does New Zealand need? Auckland: New Zealand Institute. Retrieved January 29, 2012, from http://www.nzinstitute.org/Images/uploads/Broadband\%20aspiration\%20Sep t\%202007.pdf

New Zealand Labour Party. (2011, October 17). Digital Nation: Information and Communications Technology Policy 2011. Retrieved from Red Alert: http://blog.labour.org.nz/wp-content/uploads/2011/10/ICT-policy.pdf

New Zealand National Party. (2011, November 13). Broadband and Communications Policy 2011. Retrieved from New Zealand National Party: http://www.national.org.nz/files/2011/Broadband_and_Communications_poli cy.pdf

NZIER. (2003). The economic impact of the Telecommunications Service Obligation: report to Vodafone NZ Ltd. Wellington: New Zealand Institute for Economic Research. Retrieved from http://nzier.live.egressive.com/sites/nzier.live.egressive.com/files/4120\%20E conomic\%20impact\%20of\%20the\%20Telecommunications\%20Service\%20 Obligation.pdf

OECD. (2008a). Broadband growth and policies in OECD countries. OECD. doi:10.1787/9789264046764-en

OECD. (2008b). Shaping policies for the future of the Internet economy. Paris: Organisation for Economic Cooperation and Development. Retrieved February 26, 2012, from http://www.oecd.org/dataoecd/1/29/40821707.pdf

OECD. (2011). National Broadband Plans. OECD Digital Economy Papers(181). doi:http://dx.doi.org/10.1787/5kg9sr5fmqwd-en 
O'Neill, R. (2007, July 30). Broadband bidding war not on cards for NZ, says Key. Computerworld. Retrieved January 23, 2012, from http://computerworld.co.nz/news.nsf/netw/1A2A937FA526B93DCC2573240 077E989

Papacharissi, Z., \& Zaks, A. (2006). Is broadband the future? An analysis of broadband technology potential and diffusion. Telecommunications Policy, 30(1), 64-75. doi:10.1016/j.telpol.2005.08.001

Patterson, R. (2008, May 8). Speech to TUANZ Telecommunications Day. Retrieved March 12, 2010, from Commerce Commission: http://www.comcom.govt.nz/assets/Imported-from-oldsite/TheCommission/MediaCentre/Speeches/ContentFiles/Documents/comco m-rosspattersontuanztelecommunicationsdaypresentation.pdf

Patterson, R. (2011). Regulation of Telecommunications: the lessons learned over the last 25 years and their application in a broadband world. Paper to 22nd Annual Workshop of the Competition Law and Policy Institute of New Zealand. Commerce Commission. Retrieved January 12, 2012, from http://www.comcom.govt.nz/assets/The-Commission/Speeches/RossPatterson-Paper-to-CLPINZ-Workshop-5-August-2011.pdf

Pullar-Strecker, T. (2009, August 28). John Key talks up rural broadband. Retrieved August 19, 2011, from http://www.stuff.co.nz/technology/2779396/JohnKey-talks-up-rural-broadband

Richardson, J. (2000). Govenrment, interest groups and policy change. Political Studies, 48, 1006-1025. Retrieved December 17, 2011, from http://www.politicalstudies.org/pdf/richardson.pdf

Ryall, T. (2001, December 18). Telecommunications Bill, third reading. New Zealand Parliamentary Debates.

Swain, P. (2001, October 10). Regional hi-speed Internet pilots. Wellington: New Zealand Government. Retrieved January 14, 2012, from http://www.beehive.govt.nz/node/12025

Swain, P. (2004, May 19). Decision on Telecom network recommendations . Retrieved from Beehive: http://www.beehive.govt.nz/?q=node/19750

TCF. (2012, Februray 13). Letter to Minister of Communications: CFH's Future Role. Auckland: Telecommunications Carriers' Forum. Retrieved February 26, 2012, from http://computerworld.co.nz/news.nsf/95eaeee6e6bec0c6cc2576bf00016fef/d6 dd842ec72c3778cc2579a6006eedd4/\$FILE/TCF\%20CEO\%20Forum\%20lett er\%2013Feb2012.pdf 
Telecom. (1998). Annual Report. Telecom. Retrieved January 19, 2011, from http://library.corporate-ir.net/library/91/919/91956/items/294547/telecom1998-annual-report-full.pdf

Telecom. (2003, October 29). Telecom's response to the Commerce Commission's draft report. Retrieved July 17, 2011, from http://www.telecom.co.nz/binarys/llu_comcom_draft_report_issues_paper1.p df

Telecom. (2008). Telecom Separation Undertakings: as provided to the Minister of Communications on 25 March 2008 in accordance wiht s 69K(2)(c) of the Telecommunications Act 2001. Telecom. Retrieved February 25, 2012, from http://www.med.govt.nz/sectors-industries/technology-communication/pdfdocs-library/communications/telecom-separation/telecom-separationundertakings.pdf/at_download/file

Tooland, J., \& Yoong, P. (2007). Taking a punt on broadband: regional initiatives in New Zealand. Proceedings of the Fifteenth European Conference on Information Systems (pp. 2185-2196). University of St. Gallen. Retrieved January 22, 2012, from http://aisel.aisnet.org/ecis2007/36

TUANZ. (2006, August). Telecommunications Amendment Bill 2006: Submission to Select Committee on Finance and Expenditure. TUANZ. Retrieved January 17, 2012, from http://www.tuanz.org.nz/library/c128f949-f08d-433f8985-7ff583477793.cmr

TUANZ. (2008). Towards a National Digital Architecture. Auckland: Telecommunications Users Association of New Zealand (Inc). Retrieved June 14, 2011, from http://www.tuanz.org.nz/library/b6a44a64-31ea-43619548-93750af17f49.cmr

Tye, W., \& Lapuerta, C. (1996). The economics of pricing network interconnection: theory and application to the market for telecommunications in New Zealand. Yale Journal on Regulation(13), 419-500. Retrieved January 17, 2012, from http://heinonline.org.helicon.vuw.ac.nz/HOL/Page?handle=hein.journals/yjor $13 \&$ collection=journals\&index=journals/yjor\&id=425

Varian, H., \& Shapiro, C. (1999). Information rules: a strategic guide to the network economy. Boston: Harvard Business Schoo lPress.

Vogel, S. K. (1996). Freer markets, more rules. Ithaca, N.Y.: Cornell University Press.

Vogelsang, I. (2003). Price regulation of access to telecommunications networks. Journal of Economic Literature, XLI(3), 830-862. doi:10.1257/002205103322436205 
Williams, T. (2011). Connecting Communities. Auckland: Huawei Technologies (NZ) Co Ltd. Retrieved June 26, 2011, from http://huawei.co.nz/nz/downloads/PDF/Connecting-Communities-WhitePaper.pdf

Williamson, M. (2001, May 9). Telecommunications Bill, first reading debate. New Zealand Parliamentary Debates. 